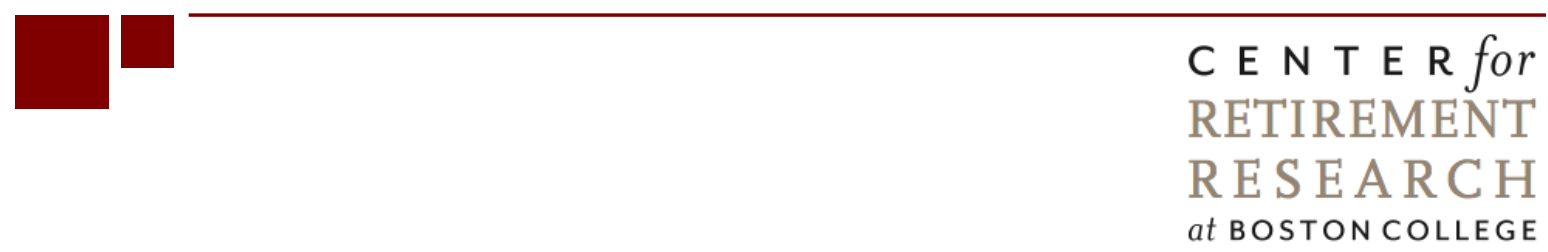

\title{
FAMILY TRANSFERS WITH RETIREMENT-AGED ADULTS IN THE UNITED STATES: KIN AVAILABILITY, WEALTH DIFFERENTIALS, GEOGRAPHIC PROXIMITY, GENDER, AND RACIAL DISPARITIES
}

\author{
Ashton M. Verdery, Jonathan Daw, Colin Campbell, and Rachel Margolis \\ CRR WP 2017-9 \\ August 2017
}
Center for Retirement Research at Boston College Hovey House 140 Commonwealth Avenue
Chestnut Hill, MA 02467
Tel: 617-552-1762 Fax: 617-552-0191
http://crr.bc.edu

Ashton M. Verdery and Jonathan Daw are assistant professors of sociology and demography at Pennsylvania State University. Colin Campbell is an assistant professor of sociology at East Carolina University. Rachel Margolis is an associate professor of sociology at the University of Western Ontario. The research reported herein was pursuant to a grant from the U.S. Social Security Administration (SSA) funded as part of the Retirement Research Consortium. The findings and conclusions expressed are solely those of the authors and do not represent the views of SSA, any agency of the federal government, Pennsylvania State University, East Carolina University, the University of Western Ontario, or Boston College. Neither the United States Government nor any agency thereof, nor any of their employees, makes any warranty, express or implied, or assumes any legal liability or responsibility for the accuracy, completeness, or usefulness of the contents of this report. Reference herein to any specific commercial product, process or service by trade name, trademark, manufacturer, or otherwise does not necessarily constitute or imply endorsement, recommendation or favoring by the United States Government or any agency thereof.

(C) 2017, Ashton M. Verdery, Jonathan Daw, Colin Campbell, and Rachel Margolis. All rights reserved. Short sections of text, not to exceed two paragraphs, may be quoted without explicit permission provided that full credit, including (c) notice, is given to the source. 


\title{
About the Steven H. Sandell Grant Program
}

This paper received funding from the Steven H. Sandell Grant Program for Junior Scholars in Retirement Research. Established in 1999, the Sandell program's purpose is to promote research on retirement issues by scholars in a wide variety of disciplines, including actuarial science, demography, economics, finance, gerontology, political science, psychology, public administration, public policy, sociology, social work, and statistics. The program is funded through a grant from the Social Security Administration (SSA). For more information on the Sandell program, please visit our website at: http://crr.bc.edu/?p=9570, send e-mail to crr@bc.edu, or call (617) 552-1762.

\section{About the Center for Retirement Research}

The Center for Retirement Research at Boston College, part of a consortium that includes parallel centers at the University of Michigan and the National Bureau of Economic Research, was established in 1998 through a grant from the Social Security Administration. The Center's mission is to produce first-class research and forge a strong link between the academic community and decision-makers in the public and private sectors around an issue of critical importance to the nation's future. To achieve this mission, the Center sponsors a wide variety of research projects, transmits new findings to a broad audience, trains new scholars, and broadens access to valuable data sources.

\author{
Center for Retirement Research at Boston College \\ Hovey House \\ 140 Commonwealth Ave \\ Chestnut Hill, MA 02467 \\ Tel: 617-552-1762 Fax: 617-552-0191 \\ http://crr.bc.edu
}

Affiliated Institutions:

The Brookings Institution

Syracuse University

Urban Institute 


\begin{abstract}
This paper examines transfers of time and money between retirees and their children. It uses data from the Panel Study of Income Dynamics to test whether numbers of children, parentchild wealth differentials, geographic proximity, and gender contribute to racial and ethnic differences in transfers of time and money between retirement-aged adults and their children. Critical components of the analysis include measuring kin availability, the spatial and social embeddedness of family networks, supply as well as demand for transfers, and gender. Key limitations are that we exclude those who have no living family members with whom they could transfer, and we do not examine the role of non-familial transfers.
\end{abstract}

The paper found that:

- There are large racial disparities in family transfers; non-White older adults are less likely to give either time or money transfers to their children than White older adults. NonWhite older adults are also less likely to receive time transfers from their children, but they are more likely to receive money transfers from them.

- Having more children is associated with marginal declines in the likelihood of transfer with each child, but an overall increase in the likelihood of transfer with any child.

- Parents who live closer to their children tend to provide more time to them and receive more time from them, while those in the same family provide more money.

- Parents who are relatively wealthier than their children are more likely to give them money and are less likely to receive time or money from them.

- Racial disparities in transfers appear to be growing across parental birth cohorts.

The policy implications of these findings are:

- Challenges regarding retiree financial security and the availability of informal care from family members are likely to grow because adults with fewer children receive less overall support than those with many children, and historical declines in birth rates mean that more older adults increasingly have fewer children.

- Older adults may be more likely to receive instrumental care, but not financial support, from their children in the future, because people are increasingly likely to live close to their children, and closer children are more likely to provide such care. 
- There may be especially large unmet financial and instrumental needs for female and non-White population subgroups of retirees. 


\section{Introduction}

Financial transfers are a common, consequential, and well-studied aspect of retirees’ family life (Cooney and Uhlenberg 1992; Edin and Lein 1997; Hao 1996; Joulfaian 2014; Lee and Aytac 1998; Stack 1975). Parents tend to give more money to their less well-off children, and children give less if their parents or in-laws are wealthy (McGarry and Schoeni 1995). Similar processes have been observed for other forms of instrumental transfers, where those with greater need receive more gifts of time (Hofferth 1984; Hogan, Hao, and Parish 1990; Sarkisian, Gerena, and Gerstel 2007; Sarkisian and Gerstel 2004). Prior work has examined whether within-family transfers are motivated by altruism or represent exchanges for received or expected services (Becker 1974; Bernheim, Shleifer, and Summers 1985; Cox 1987; Cox, Hansen, and Jimenez 2004; Cox and Rank 1992; Hogan, Eggebeen, and Clogg 1993; McGarry and Schoeni 1995). In the context of this research, many have noted that there are prominent racial differences in transfer patterns (Berry 2006; Lee and Aytac 1998; McKernan et al. 2014), which are strong enough to account for 12 percent of the very large racial wealth gap (McKernan et al. 2014).

However, existing work on transfers within families has neglected important social processes that make transferring more or less likely, namely: 1) the availability of living kin to transfer; 2) the geographic proximity of kin; and 3) the constellation of family obligations created by gendered familial roles. In this paper, we add these social and demographic factors into the study of retirees' transfer patterns to test whether they contribute to racial differences in transfer behaviors among those aged 50 and above. We use novel data extracted from publicly available and restricted versions of the 2009 and 2013 waves of the Panel Study of Income Dynamics (PSID) to examine factors that are associated with retirement aged individuals giving and receiving transfers to and from their children. We focus on transfers of time and money in the past year, and we look at both parent and child reports of such transfers. We place special emphasis on parent gender, parent birth cohort, and parent race. Crucially, our models investigate the role of kin availability by exploring the relative transfer behavior of parents with more or fewer children. We also examine child attributes, such as age group and gender, as well as differences between children and parents in terms of wealth and geographic proximity of kin. In addition to considering several understudied correlates of transfers, this study contributes to the literature by a) comparing across transfer types and directions; b) 
comparing between a larger range of birth cohorts while prior work has focused on earlier birth cohorts; and c) examining data that represent the a fuller range of transfers in contrast to prior work, which has tended to use censored data that inflate and otherwise distort racial discrepancies.

Our results suggest that kin availability, measured as the number of children a parent has, is a strong negative predictor of transfers between parents and individual children. Those with more children are consistently less likely to provide time or money to each of them, and they are less likely to receive time from each. However, the lower marginal levels of dyadic transfer among those with more children do not outweigh the greater total parent-level rates of each associated with having multiple children. Families in closer geographic proximity tend to be more likely to transfer time, but there are only limited effects on the transfer of money. Wealthier parents generally receive less time and money from their children, and are more likely to give their children time. We also find interesting gender patterns in transfer behaviors. Female children are more likely to give to their parents than male children are, but there are no meaningful differences in the likelihood of parental giving based on child gender. By contrast, female-headed households are more likely than male-headed households to receive time and money from their children, but both household types are equally likely to give both time and money.

We find parental birth cohort effects consistent with an interpretation that younger parents are more likely to give time to their children and less likely to receive it from their children than older parents, but that there are no differences by parental birth cohort in the likelihood of giving or receiving money. Child age tends to exhibit a U-shaped relationship with the probability of receiving time and money from parents, such that middle-aged children are the least likely to receive such transfers. Finally, we find persistent racial disparities in the likelihood of giving and receiving transfers. Non-White retirement age parents tend to be less likely to give time and money to their children, and they are also less likely to receive time from their children. They are, however, more likely to receive money from their children. Transfer pattern differences by race appear to be changing across parental birth cohorts such that disparities are growing over time for the transfer of time from parents to children but shrinking over time for the transfer of money in this direction. Racial disparities in parental receipt of time 
transfers appears to be growing again after shrinking among cohorts born during the Great Depression, and they are growing for parental receipt of money transfers.

Finally, we find that child demographic characteristics, numbers of children, parent-child wealth differences, and parent-child geographic distances together plan an important mediating role in creating racial/ethnic disparities in parent-child transfers, especially for financial exchange. These factors explain 56 percent of the Black-White difference in parents giving money to children and conditionally increase the Black-White gap in parental funds received by 24 percent, but explain only 15 percent and slightly expand that gap for parental time given and received, respectively. Similar patterns are found for Hispanics - these factors explain 36 percent of parental financial giving and expand the gap versus White retirement aged adults for financial support received by 51 percent, but reduce the time given gap by 9 percent and increase the time received gap by 7 percent. Therefore, number of children and child demographic, spatial, and socioeconomic characteristics are important factors for understanding racial and ethnic disparities in financial exchange between parents and children, but less so for time exchange.

\section{Background}

Even in developed countries like the United States, transfers of financial resources and time within families is a common means of both "making ends meet” and building wealth (Cooney and Uhlenberg 1992; Edin and Lein 1997; Hao 1996; Stack 1975). Retirees are a particularly important group in which to study patterns of family transfers. Transfers between retirees and their families have implications for individuals' health and well-being (Gaugler et al. 2007; Luppa et al. 2009), for their wealth and retirement income (Modigliani 1988), for public policy surrounding retirement and taxation (Barro 1974), and for intergenerational inequality (Gale and Scholz 1994). Families invest considerable time in one another by engaging in activities such as providing free childcare (Hofferth 1984; Hogan et al. 1990) or eldercare (Rossi 1990; Stein et al. 1998). Billions of dollars move between households via within-family cash transfers, with the majority (60 percent) flowing from parents to children (Joulfaian 2014; Lee and Aytac 1998). Understanding the factors associated with time and money transfers within families is consequential at both the micro and macro levels. 
Much previous research on this topic has sought to adjudicate between different implicit models of human behavior underlying family transfers. For instance, many have studied financial transfers in the context of a debate about motivations, particularly whether transfers are motivated by altruism or if they are motivated by perceptions of exchange for received or expected services (Becker 1974; Bernheim et al. 1985; Cox 1987; Cox et al. 2004; Cox and Rank 1992; Hogan et al. 1993; McGarry and Schoeni 1995). Other perspectives include the idea that such transfers are a form of risk-sharing (Gordon and Varian 1988), and that they are heavily governed by norms of equal bequeathing to children (Wilhelm 1996). The literature is mixed in terms of support for these different models, though the altruism model has more support in the recent literature than the others (McGarry 2012). Numerous studies have shown that parents tend to give more money to their less well-off children and that children give less to affluent parents (McGarry and Schoeni 1995). Other forms of transfers that can be broadly summarized as transfers of time behave similarly, where those with greater need receive more gifts of time.

Despite debates and mixed results about motivations for transfers within families, the literature consistently demonstrates an empirical regularity: non-White families are less likely to engage in financial transfers (Berry 2006; Lee and Aytac 1998; McKernan et al. 2014). There is, however, considerable debate about race and ethnic differences in non-financial transfers. Early work on this topic highlighted tradeoffs between financial and non-financial transfers: White Americans are more likely than Black Americans to transfer money, but Black Americans are more likely to transfer non-financial resources like free child-care (Hofferth 1984; Hogan et al. 1990). This finding has been observed in more recent studies as well, with work showing that while White families are more likely to receive financial transfers, non-White families are more likely to receive time transfers such as child or elder care (Sarkisian and Gerstel 2004). Few studies examine racial and ethnic differences beyond a Black-White dichotomy, but recent work suggests that the largest Hispanic group, Mexican Americans, tend to engage in more time transfers with kin but fewer financial transfers (Sarkisian et al. 2007); though the time transfer effect is only evident among women. Our project has important implications for this debate: part of the "advantage" of non-White retirees in terms of time support may owe to differences in the number, geographic dispersion, and gender composition of their children than White families.

Among those with parents age 51-61 in 1995, 18 percent of White children received cash gifts of more than $\$ 500$ while only 11 percent of non-White children received such gifts 
(McGarry and Schoeni 1995). Contemporaneous results from a different data source found starker differences (18 percent vs. 6 percent; (Lee and Aytac 1998)). Non-White families are not only less likely to receive gifts from their parents, they are more likely to give them. Among parents drawn from the same group, only 7 percent of White parents received such gifts from their children; the comparable number for non-White parents was 15 percent. Gifts of time exhibited fewer, almost indistinguishable racial disparities, at least in the direction from children to parents. More recent analyses of families from 1999-2007 that did not exclude smaller gifts $(<\$ 500)$ showed similar results, suggesting that non-White households receive considerably fewer dollars in financial transfers from relatives than White households, though non-White families were somewhat more likely to receive a transfer of any kind (McKernan et al. 2014). Racial differences in the receipt of large gifts $(>\$ 10,000)$ were especially notable, with nonHispanic White families 5 times more likely to receive them than other groups. This work shows that non-White families receive less from and give more to their family members than White families. The authors maintain that such group differences, especially in large gifts, account for 12 percent of the racial wealth gap (McKernan et al. 2014).

We apply insights from the fields of demography and social network analysis that grant us a key analytical perspective that we bring to bear to help understand these group differences. We focus on understanding not just who gives and receives transfers, but who is at risk of giving or receiving transfers, whether or not they do. Attention to such “populations at risk” is a core issue in the demographic literature, and it is mirrored in the literature on social networks and social capital where differences between "function” and "structure” of social networks (Daw, Verdery, and Margolis 2016) or “mobilization” and “access” to social capital (Lin 1999) are paramount considerations. Relatedly, we approach the family as a network, meaning that it is a social unit composed of a series of dyadic ties, which together comprise the whole. These perspectives orient us toward understanding not just who has received transfers - but from whom. Both the giver and the receiver are united, as transfers fundamentally concern two individuals. We are interested in differentiating those pairs that complete a transfer from those who do not. Our approach permits us to calculate the rate at which families of different types engage in different kinds of transfers, because the ties that do not provide assistance are measured along with the ties that do. In addition, we are interested in the embeddedness of these processes within family networks. To understand transfers between pairs of people, it is vital to 
understand the possible and achieved transfers between others to whom the members of the pair are connected. The resources and motivations for transfers must be examined within this broader context of demand and supply of resources in the family network.

In the extensive literature on the transfer behavior of retirees and their families, we argue that demographic and network processes and insights have not received the attention they deserve. The prior literature has largely neglected the social processes that intervene along the way to exchanging with kin. Three features in particular deserve attention: 1) the availability of living kin to transfer with, 2) the probable frequency of contact between living kin as a partial function of geographic proximity and gendered familial roles, and 3) the constellation of family obligations created by these two processes. We focus on these three items because of their strong differences between racial groups, and we question whether they enhance or attenuate racial differences in familial transfers. That is, we ask: what might demographic and social network factors in transfers add to existing economic models of supply and demand and motivations?

The first neglected domain in research on transfers is the availability of kin to transfer with. White and non-White Americans have a long history of divergent mortality and fertility levels, and neglecting the effects of this historical demography on available kin may bias understandings of transfers. Large racial differences in mortality (Rogers, Hummer, and Nam 1999), fertility (St. John 1982), and marriage/partnership rates (Manning and Smock 1995) will produce differences in available kin (Verdery 2015). Recent studies of the distribution of American kinship networks (Daw et al. 2016) find that pre-retirement and retirement age (55+) White adults were substantially more likely (8 percent vs. 4 percent) to have two living parents and less likely (61 percent vs. 77 percent) to have none. White adults in this age range have more living children on average too, with the adjusted proportions having $0,1,2$, 3, and 4+ children for White adults being $0.22,0.21,0.32,0.16,0.09$, respectively, while the same sequence of proportions for Black adults is $0.29,0.24,0.29,0.12$, and 0.06 . Racial differences in mortality, even of children, are also significant and an understudied source of racial disparities (Umberson et al. 2017). By age 50, Black children are 29 percent more likely to have experienced the death of their mother and 10 percent more likely to have lost a father to death than White children (Umberson et al. 2017). They are also twice as likely to have lost a child, although this is a much rarer event (Umberson et al. 2017). Racial disparities wherein White 
adults in their retirement ages are more likely to transfer with their children than non-White adults of the same age may be explained by the simple fact that they have more living parents and children due to lower kin mortality rates. Thus, Whites and non-Whites could have the same kin-specific probability of transfer, but larger numbers of kin to create a disparity, which is a very different mechanism than differences in kin-specific transfer rates.

The second neglected domain in prior research on retiree's transfer behaviors is the geographic embeddedness of relationships. When families live further apart, they may not be in touch or communicate infrequently, may not be aware of the needs of their kin, or may be unwilling to ask of or give to them because of a less strong bond. Both awareness of need and willingness to request and give are key non-economic determinants of transfer in all models of familial transfers, but they, to our knowledge, have never been directly examined as a potential moderator of transfer in prior studies. Constrained by available data, we focus on the geographic proximity of family members and assume that it captures the possibility of information transmission that would motivate transfers. Contact is easier to maintain when kin live near one another, but there is some evidence that Whites and non-Whites have differential rates of living near their kin (Daw and Verdery 2014). We hypothesize that spatial distance will play an especially important role in determining transfer frequency and may explain a portion of racial disparities in transfers.

Gender is also likely to be an important factor in determining transfer rates, because a well-established sociological finding holds that women are "kin keepers" in a variety of social contexts (Hagestad 1986; Spitze and Logan 1990). Differential expectations of gendered familial roles by race may account for racial discrepancies in transfers, however.

Finally, prior work on familial transfer has taken an "under-socialized” view (Granovetter 1985), ignoring the embeddedness of individuals within a constellation of obligations. A child's obligation to support a struggling parent may be outweighed by his obligation to support a more struggling parent-in-law, or it may be offset by an affluent sibling with a greater supply of resources to transfer. Prior work has tended to look at dyadic transfer to the neglect of the situations of other family members; simply controlling for numbers of family members does not solve this problem. In geographically dispersed and differentially gendered family networks, we may expect that the combination of these factors affect racial differences in patterns of transfer. For example, there are interesting questions to ask about the pre-retirement aged older cohorts of 
the "sandwich generation", those with both young adult children and elderly parents, where research has shown that transfer tend to flow toward children (Fingerman et al. 2010, 2015). At the same time, that work in specific ignores the demographics and network embeddedness of these processes, wherein those cohorts are more likely to have more or as many young adult children in need as living parents, with whom burdens of transfer can be distributed among siblings.

\section{Data and Methods}

Data

We use data from the Panel Study of Income Dynamics (PSID). The PSID originally sampled a nationally representative panel of households containing over 18,000 respondents in 1968. The PSID is a household panel with a branching, genealogical design. The study follows all living, non-attrited members of the original households as they progress through the lifecourse, and, in addition to the original sample respondents, it adds all co-resident members of households in which PSID respondents reside to the list of survey participants in each sample wave. From the original data collection until the present, the PSID conducted interviews annually until 1997 and biennially after that. Over its nearly five decades of existence, the PSID has interviewed more than 70,000 respondents. We use the 2013 PSID Family file, the 2013 Rosters and Transfers Parent/Child file, and 2009 geospatial data from the PSID that measures respondent household locations at the Census Tract level.

The 2013 PSID Family file contains data on 24,952 individuals in 9,063 respondents. These data provide more than 5,000 measures of variable respondent attributes, including sex, age, race, wealth, and household census tract. Because of its genealogical design, the PSID lost its representativeness of the national population over time. To cope with changes in the national composition owing to immigration, the PSID added supplementary samples of Latino households in 1990. Despite not being nationally representative, the PSID is broadly considered a high quality survey with high response rates, low attrition, and high coverage of the target population (Duffy and Sastry 2012).

The PSID is ideal for studying retirees' transfer patterns with family members, especially because of new modules developed specifically for this purpose (Schoeni et al. 2015). The 2013 Family Roster and Transfer Module contains information on heads of households and their 
partners in the 2013 wave of the PSID, and the short- and long-term transfers of time and money they have received and given to their parents and children since the involved parties were 18 years old. These data encompass information on 23,967 parent-child pairs. Thus, this dataset is a critical and entirely original resource spanning three generations of Americans and the time and financial resources they have transferred, nested in rich, decades-long data on their extended kin relations, household formation practices, geographic distance networks, and detailed socioeconomic fortunes. This data contain complete records on each parent to each head/wife of household as well as their children and the transfers that have been completed between pairs of each type. Each record in the dataset consists of a parent/child dyad. The file contains reports of transfers of time and money from both parents and children and it distinguishes in which direction the transfer occurred, from parents to children and from children to parents. We focus on parent reports of the transfers they gave to or received from their children. In future work, we will consider reports from the opposite direction.

However, one limitation of the Family Roster and Transfer Module data for present purposes is that many of these parent/child pairs did not both participate in the main PSID study. This would pose no difficulty if all variables that we wanted to examine were contained in the Family Roster and Transfer Module dataset, but many factors are not - including parent and child wealth, geospatial location, ${ }^{1}$ and race/ethnicity. Therefore, in our analysis the sample size is reduced to 5,204 parent-child pairs who both participated in the main PSID and were not missing data on any of the variables examined.

The PSID is the only data source that includes rich enough information of family systems over time, their location, and transfers within them, to answer these proposed questions. Another advantage of the PSID over other plausible candidate data sets, like the Health and Retirement Study, is that its measures of transfers are not truncated in such a way as to inflate and otherwise distort racial disparities (McGarry and Schoeni 1995). The Health and Retirement Study only collected data on transfers greater than $\$ 500$ in the past year, while the PSID collected data on transfers greater than $\$ 100$ in the past year. We are also interested in how birth-cohort and lifecourse differences affect estimates of racial disparities in transfers. Prior work has most

\footnotetext{
${ }^{1}$ These data are available under a restricted contract, which we are presently negotiating. In the meantime we are limited to using the 2009 restricted geospatial data to which we already had access, which is only available for main study PSID households.
} 
commonly focused on the 1930 birth cohort, or else more recent birth cohorts measured long before retirement ages. We look at parents born during a five decade span of cohorts between 1914 and 1963, who together have lived at least 50 years each in 2013. This range of birth cohorts allows us to explore how racial and ethnic disparities in transfers differ across a wider set of parental birth cohorts than prior studies have examined.

\section{Focal Outcomes}

We examine eight focal outcomes by looking at the provision and receipt of time and money transfers. For discursive clarity, we index our discussions of these phenomena from the parent's perspective; thus, when referring to provision of time we mean the parent provides time to the child, while when referring to receipt of money we mean the parent receives money from the child. In the main text, we analyze parental reports of what they provided to or received from their children. For each type of transfer, in each direction, we consider both the existence of the transfer and, if it exists, its amount. We examine transfer existence using a dichotomous variable coded into whether or not a transfer occurred among all parent/child pairs in the data. We examine amounts transferred only among the subset of parent/child pairs that have an existing transfer. Amount of time is measured in hours transferred in 2012, while the amount of money is measured in dollars transferred in 2012. There is a minimum \$100 threshold for dollar transfer amounts. We first examine parents' provision of time to their children, then we examine their provision of money, then we examine their receipt of time from their children, and last we examine their receipt of money.

\section{Independent Variables}

We model parents’ provision and receipt of time and money transfers using a straightforward set of socio-demographic predictors that capture the ascribed and achieved attributes of both parents and children. For each parent, whether they are from a female-headed household (male-headed household is the reference category), their birth cohort, their race or ethnicity, and the number of living children they have (measured as the number of child records they have in the Rosters and Transfers file). We set those born 1914-1934 as the reference category for birth cohort, and we compare them against those born 1935-1944, those born 19451954, and those born 1955-1963. The reference category for race and ethnicity is non-Hispanic 
White (hereafter White), which we compare against non-Hispanic Black (hereafter Black), Hispanic, and other races or ethnicities (hereafter Other race). Those without living children are not in the data we examine, so we set the reference category for number of living children as one child, and we compare those individuals against others who have two children, three children, or four or more children. For each child, we measure their age group (reference category is 17-34, compared to 36-50, and 51 and above), and whether they are female (male is reference category).

An important consideration is the wealth differential between parents and children. We measure the difference between parent and child wealth by taking the decile of the difference in parent wealth minus child wealth, multiplied by ten. Our wealth differential variable is thus expressed in deciles in the interests of coefficient interpretability, ranging from 0 to 9 , with a value of zero indicating that there is a low wealth differential between parents and children (and, in some cases, that children are wealthier than their parents), while a value of ten indicates that the parent is much wealthier than his or her child. Note, for this measure we use the PSID measure of wealth that includes home equity.

Last, we measure the geographic distance between parents and children in 2009. Because the spatial information provided by the PSID is only available at the tract level, we measure each household's geographic location as the spatial centroid of the Census tract in which they reside. We calculate the distance in miles between each kin pair's Census tract centroids using the (Vincenty 1975) equation based on WGS 1984 reference ellipsoid that allows for the Earth's curvature. This strategy results in left truncation of the spatial distance distribution, as some kin pairs will live in the same tract but not in the same household but both would be considered 0 miles apart. To measure geographic proximity, we employ two variables. The first is an indicator variables measures whether the pair coresides or not (reference category is noncoresident pair). The second measures the distance between the pair's census tract centroids, measured linearly in 100s of miles. Using these two variables, we can distinguish coresident from non-coresident individuals living in the same census tract.

\section{Analyses}

We examine our research questions through multivariate regression techniques. All models are run as linear probability models (whether given or received) or ordinary least squares regressions (amount given or received conditional on any). Using linear probability and ordinary 
least squares regression models facilitates model to model comparisons of coefficient magnitude and significance - comparisons that are not valid in more traditional logistic or probit regression models. We handle missing data by using list-wise deletion in all models. For our models of amounts transferred, which are conducted on the subset of cases that engaged in any transfers, we only include White and Black respondents due to the limited sample sizes for Hispanics and other race parents.

For each of our eight outcomes of interest, our models proceed sequentially to add additional controls. First, we model only ascribed parent characteristics (i.e., all parent factors excluding number of living children, wealth differences between parents and children, the coresidence indicator, and the geographic distance between the parent and the child). These models allow us to develop a baseline understanding of transfer disparities and how they vary by race and ethnicity. Then we model achieved parent characteristics and all child factors; these models include parent/child wealth differentials, coresidence, and distance. Comparing these models to the models with only ascribed parental characteristics allows us to understand how different factors affect transfer disparities. Third, we use parental fixed effects that controls for all unobserved characteristics of the parent head of household. These models allow us to examine the effects of family embeddedness. By controlling for the reporting parent, all parental attributes drop out of the model and the focus becomes on how parents of different types of children provide or receive transfers from them. For instance, the effect of a child gender (child is female) in the fixed effects models should be interpreted as the amount that sisters compared to brothers receive from or give transfers to their parents. Note, the fixed effects models exclude parents with only one child as well as those whose children's attributes do not vary.

We also fit models that controlled for interactions of parent race and ethnicity by parent birth cohort to assess changes over time in parental provision and receipt of transfers; we present these results as plots of the marginal probabilities and amounts in the main text, with the coefficients from these regressions available in Appendix Table A1. These results allow us to characterize whether racial and ethnic differences in transfer probabilities are changing across birth cohorts. Given that these data were collected at one point in time, during the PSID’s Roster and Transfers module in 2013, one way to think of a change across birth cohorts is that it reflects the potential for future changes through the mechanism of demographic metabolism and cohort succession (Lutz 2013). If successively younger cohorts exhibit greater disparities in transfer 
probabilities, then we might expect that the population level disparities in transfer will widen as cohorts age and members of the older cohorts die. Another way to think of cohort changes in transfer probabilities is as an age effect; perhaps as parents age they become more similar in rates of giving or receiving transfers. Finally, a third way is to interpret these effects as indicative of survivorship bias, especially if parents from each cohort who are more involved in family exchange were more likely to survive to 2013. Without longitudinal data or at least repeated cross-sections, it is difficult to separate the independent influences of cohort, age, and survivorship effects.

\section{Results}

\section{Descriptive Statistics}

Table 1 shows the descriptive statistics for the analytic sample. We report all results at the unit of analysis level, which differs slightly from the numbers of parents or children in the data set because the units of analysis in our models are dyads and each parent, for instance, can have multiple children in the sample and thus appear in multiple dyads. About 32 percent of parents report giving time to their children, with the average amount given by those who do being approximately 366 hours in the past year. Fewer parents report receiving time from their children, about 25 percent, while the amounts received are lower as well, about 324 hours in the past year. Approximately 31 percent of sample members report giving money to their children. Those who give money report giving close to $\$ 3100$ in the past year. A very small proportion, about 9 percent of parents in the sample, report receiving money from their children; among those who do, they report receiving about $\$ 600$ in the past year. Because of the conflation of parental household structure and parent gender, only 34 percent of parents in the sample are women. The most recent birth cohort, those born in 1955-63 are the most prevalent in the sample, accounting for about 43 percent of all parents. Other cohorts make up progressively smaller shares the earlier in the $20^{\text {th }}$ Century they were born. For children, the most common age group is the omitted category of young adults, followed by those aged 36-50. There are few dyads in the data set where the child is above 50 years old; such cases comprise approximately 13 percent of dyads we analyze. About half of children records in the data set are female. Owing to the overrepresentation of parents with many children in the dyad based sample, the plurality of records are for children of parents with four or more children. As would be 
expected, the average decile in the wealth difference distribution is about 5. Most pairs in the data live close to one another, an average of about 138 miles. Finally, about 30 percent of pairs in the data live in the same household.

\section{Parents Giving Time to Their Children (Parent Reports)}

Table 2 shows results for our models of parent reports of their own provision of time to their children. Models 1 through 3 examine whether the parent provided any time, regardless of amount, while Models 4 through 6 examine the amount of time in hours provided conditional on the parent providing any. Models 1 and 4 contain only ascribed parent attributes. Models 2 and 5 contain parent and child attributes. Models 3 and 6 are fixed effects regressions that consider only variation between children of the same parent (and thus excludes parental characteristics from the regression model).

Considering only ascribed parent attributes (Models 1 and 4), we see no significant effects of parent gender. There is no statistically distinguishable difference in the likelihood or amount of time that mothers provide to their children compared to fathers. There are however, birth cohort effects such that younger parents - those born in later birth cohorts - tend to be increasingly more likely to give time to their children, and, when they do, they tend to give more of it. The one exception to this trend is that parents born in the 1935-1944 period who give any time to their children tend to give more than parents born in any other birth cohort who give time to their children. We also see substantial differences by parent race and ethnicity. White parents give the most time to their children. Compared to White parents, Black parents are approximately 10 percent less likely to give time to their children, Hispanic parents are 20 percent less likely, and other race parents are 16 percent less likely.

We next add child attributes, the number of children the parent has, the wealth difference between the parent and child, and geographic factors to the regressions. These results are presented in Models 2 and 5. In these regressions, the effects of parental birth cohort are greatly reduced, with effect sizes in Model 2 approximately half as large as those in Models 1 and no statistically significant effects in Model 5. Comparing across Models 1 and 2, which model likelihood of transfers, we see that the Black-White race difference also declines when controlling for child attributes, achieved parental characteristics, and parent/child differences, from approximately 10 percent to approximately 9 percent, while race and ethnic differences 
between Hispanic and White parents decline from 20 percent to 19 percent, and the difference between other race and White parents remains approximately equivalent. Comparing across Models 5 and 6, which model amount of transfers if any, we see that the inclusion of child attributes negates the effects of parent birth cohort but does not substantially alter the effects of parent race and ethnicity. With both parent and child attributes controlled, Black parents who report providing any time assistance to their child transfer approximately 221 more hours of time per year to their children than White parents who do so. We find it helpful to consider the magnitude of these numbers in terms of eight hour workdays, perhaps spent providing free childcare to grandchildren; in this case, these results suggest that Black parents report providing approximately 28 more workdays per year to their children than White parents report providing to their children. This is a very large effect.

Considering the child attributes, Models 2 and 5 indicate that parents are less likely to give time to older children than younger. A similar but non-significant trend is evident in the amount of time given among parents who give. Parents are about 6 percent more likely to give time to their daughters than sons, although among those giving time the amount of time given to daughters does not differ from the amount given to sons. In addition, parents with more children are less likely to give time to each individual child than parents with only one child. However, the net effects of giving to multiple children outweigh the reductions in per child giving, making parents of multiple children more likely to give than parents of only one child. We calculate this by multiplying the independent probabilities of transferring with each child (i.e., the predicted value from the regression) for parents with a given number of children by the number of children they would be transferring with. For instance, under an assumption of independence, parents of 4 children $(0.584=4 \times(0.355-0.209))$, 3 children $(0.636=3 \times(0.355-0.143))$, and 2 children $(0.520=2 \times(0.355-0.095))$, are all approximately 145 percent-180 percent as likely to give time to at least one of their children as parents of one child are to give to that child (0.355). In terms of the amount of time parents give to their children, however, we see few statistically significant differences by numbers of children. In Models 2 and 5, we find that parents who are relatively wealthier than their children are more likely to give time to them, but we do not find significant differences in terms of the amounts given by the subset of parents that give time. The further the distance between parents and children, the less likely parents are to give their children time; every 100 miles is associated with approximately a 1 percent decrease in 
the likelihood of giving time (Model 2). Parents who coreside with their children are about 5 percent more likely to give them time than parents who live in the same census tract (but not same family). There are no associations between distance or coresidence and amounts given (Model 5), however.

Next, we consider fixed effects models of parents giving time to their children (Models 3 and 6). These more stringent models support the prior findings that parents are more likely to give time to their daughters than their sons, but that they do not differ in amounts given when they provide such transfers. In the fixed effects models, the child age effects on the likelihood of giving are also largely supported, albeit with weaker effect sizes. The amount of time parents report giving to their children remain non-significant in the fixed effects models. Controlling for parental fixed effects changes the result about wealth differentials such that the positive effect seen in Model 2 is no longer significant in Model 3. This change suggests that unmodeled differences between families drive the wealth differentials effect. The average parent is no more or less likely to provide time to his poorer child than his wealthier child. Distance effects are relatively consistent in the fixed effects models. However, the effects of living in the same household change. Whereas coresident parents were more likely to give to their children in Model 2, this finding is not supported in the fixed effects model (Model 3), suggesting that the effect is due to the association of unmeasured parental characteristics with coresidence, not coresidence itself. By contrast, in the fixed effects models of amounts given, we find that parents in the same household give more time to their children.

Last, we consider birth cohort differences in time parents give to their children. Figure 1 shows predicted values from regressions that control for parent and child factors and contain an interaction term between parental birth cohort and parent race and ethnicity (full regression results available in Models 1 and 5, Appendix Table A1). Our goal in analyzing these results is to ascertain how racial and ethnic disparities are growing or shrinking across birth cohorts, in line with the interpretations of cohort succession or aging effects described above. We find evidence of increasing racial and ethnic disparities across parental birth cohorts in the probabilities of parents giving time to their children (left panel). Whereas White, Black, and Hispanic parents have roughly similar probabilities of giving time to their children in the oldest birth cohort, born between 1914 and 1934, parents of different races and ethnicities born in the 1955-1964 birth cohort have very different probabilities. The youngest White parents, born 
1955-1964, have approximately a 45 percent chance of giving time to their children, while Black parents in this cohort are predicted to transfer time in 30 percent of cases and Hispanic and other race parents are even lower, around 20 percent. We also see evidence of increasing Black-White disparities in amounts of time provided by parents who give time to their children across birth cohorts. White and Black parents in the oldest birth cohort have nearly equivalent values on this measure, but disparities grow across cohorts until White parents in the youngest birth cohort report providing almost half as much time to their children as Black parents do.

\section{Parents Giving Money to Their Children (Parent Reports)}

Table 3 shows results for our models of parent reports of giving money to their children. It has the same structure as Table 2, with Models 1 through 3 looking at probabilities of providing time and Models 4 through 6 looking at amounts provided among those who provide at least some time. Ascribed parent attributes are in Models 1 and 4, while Models 2 and 5 have all parent and child attributes, and Models 3 and 6 are the fixed effects models.

Models 1 and 4 show that many ascribed parent attributes are associated with differences in the probability of providing money to children, but that few of them except race and ethnicity are associated with the amount of money provided conditional on providing any. For instance, these results indicate that mothers are less likely to provide money to their children than fathers (Model 1), but that there are no significant differences between mothers and fathers in the amounts of money provided among those who provide any (Model 4). As with the likelihoods of providing time, Model 1 also reveals differences by parental birth cohorts in the likelihood of providing money, while Model 4 shows no differences in amounts provided by those who provide any. Race and ethnic differences are the one exception to this pattern. Black parents are about 11 percent less likely to provide money to their children (Model 1), and they provide about $\$ 2,300$ less per year when they do (Model 4). In general, the race and ethnic differences in likelihoods of providing money largely mirror those found for likelihoods of providing time, except that other race parents are more similar to White parents than other non-White groups. White parents are the most likely to provide money, then Black parents, then Hispanic parents. Similarly, in terms of the likelihood of providing money to children, younger parents are more likely to do so, just as they were with the provision of time. This difference is only evident among those born after 1945, however. 
Models 2 and 5 show the models with all parent child attributes. For the model of whether money is given (Model 2), including achieved parent characteristics, parent/child differences, and child attributes reduces the effect of parent gender, removes parent birth cohort effects, and reduces the parent race and ethnicity effects by approximately half compared to the model without child attributes (Model 1). The coefficient reflecting the amount of money provided by Black parents compared to White parents (Model 5), also declines in magnitude. Controlling for child attributes, Black parents provide about $\$ 1,800$ per year less to their children than White parents provide to theirs. As with parental attributes, many child attributes are important for the provision of money (Model 2) but not the amount of money provided conditional on providing any (Model 5). In this case, parents are less likely to provide money to older children than to younger children, about 7 percent-8 percent less likely for children over 35 compared to children in younger age ranges (Model 2), but, if they provide any money, it is approximately the same amount (Model 5). Our more fully specified models indicate no association between child gender and parental provision of money; parents are neither more likely to give money to their daughters than their sons nor do amounts given to sons or daughters differ among those that give anything. Parents with more children are less likely to give to each child, and those with the most children give substantially less to each than those with only one child. The magnitude of the effects per child on likelihoods of giving are similar for the provision of money to what they were for the provision of time, albeit slightly stronger. Parents with 4+ children give each about $\$ 2200$ less per year than parents with only one child, but other differences in terms of numbers of children are not significant. Wealth differences between parents and children are associated with increased likelihood of giving to children and increased amounts given the wealthier the parent is than the child. Parents whose wealth exceeds their child's wealth by the largest amount (a decile difference of 9) are about 23 percent more likely to give them money than parents whose wealth is comparable to or less than their child's wealth. They are also expected to give them $\$ 2900$ per year more than parents that provide money to their children who have comparable or greater wealth. The further parents reside from their children, the more likely they are to provide them with money, although the amount is not strongly affected by distance. Coresident parents are about 12 percent more likely to give their children money than non-coresident parents, and coresident parents that give their children 
money tend to give about $\$ 1500$ more per year to them than non-coresident parents who give transfer to their children.

We present the regressions with fixed effects at the parent level in Models 3 and 6. Model 3 shows a steeper gradient by child's age in the likelihood that parents give money to their children than was found in Model 2. Such parents are least likely to give money to older adult children, with differences between middle age children and young adult children nonsignificant. The fixed effects model of the likelihood of providing money (Model 3) also indicates that child gender is a significant factor: parents are about 3 percent more likely to give money to their daughters than to the brothers of those daughters (i.e., their sons). When parent fixed effects are accounted for, wealth differentials are less important for the likelihood of parents providing money to their children. Parents who fall in the largest decile of the distribution of the extent to which parent wealth exceeds child wealth are about 8 percent more likely to provide money to that child. In the fixed effects models, we see that distance is no longer significant and that the effects of living in the same household are reduced by approximately half. The fixed effects model (Model 6) highlights that parents who give transfer substantially less money to their older adult children than their young adult children. None of the parent/child differentials in terms of amounts given are upheld in this model.

Predicted values from the interactions of birth cohorts by race and ethnicity are plotted in Figure 2 full regression results available in Models 2 and 6, Appendix Table A1). Whereas we saw larger race and ethnicity disparities in more recent parental birth cohorts than older ones in parents' provision of time to their children, we see smaller race and ethnicity disparities in more recent parental birth cohorts than older ones in their provision of money to children. For instance, White parents born between 1914 and 1934 were several times as likely to provide money to their children as non-White parents, but parents of different races and ethnicities born in the 1955-64 birth cohort are almost indistinguishable in this likelihood. Hispanic parents are the exception, since they remain significantly less likely to provide money to their children than White parents, although the size of this disparity is shrinking across parental birth cohorts. In terms of amounts, where we only examine Black-White differences, we see that the amounts provided also appear to be converging across birth cohorts. White parents of all birth cohorts provide approximately equivalent amounts, while Black parents from more recent birth cohorts provide more than Black parents from earlier birth cohorts. In spite of this trend toward 
convergence, large disparities persist; even among those born in the 1955-63 birth cohort, White parents transfer about twice as many dollars as Black parents.

\section{Parents Receiving Time from Their Children (Parent Reports)}

We now turn to models of parents receiving transfers from their children. Table 4 shows models of the receipt of time; it has the same structure as Tables 2 and 3.

In terms of ascribed parent attributes, the model that only accounts for parent attributes (Model 1) and the model that controls for child attributes and achieved parental attributes in addition to ascribed parental attributes (Model 2) are relatively consistent. In Model 2, we see that mothers are about 14 percent more likely to report receiving transfers of time from their children than fathers. Parental birth cohort exhibits a concave, U-shaped relationship with the likelihood of receiving time from children. Parents in the youngest and oldest birth cohorts are the most likely to receive time from their children, while parents in the middle birth cohorts born between 1945 and 1954 are about 6 percent to 12 percent less likely to receive time transfers from their children. White parents receive more time thank Black parents (5 percent less likely than White parents) and Hispanic parents (8 percent less likely than White parents). Figure 3 indicates that birth cohort and race or ethnicity interact to produce differences in the likelihood of receiving time from children. These differences are primarily driven by the U-shaped birth cohort effect for White parents, which differs from the patterns by birth cohort observed for nonWhite parents. For instance, there appears to be only a limited birth cohort effect for Hispanic parents, which makes their youngest and oldest members significantly less likely to receive transfers of time from their children than the White parents, for whom there is a U-shaped birth cohort effect. Roughly the same pattern is evident for Black parents, although the difference between White and Black parents in the oldest birth cohort is not significant. Other race parents differ most substantially in the older birth cohort, who are much more likely to receive time transfers from children, but this is a small and select group of respondents.

Looking at child attributes and parental achieved attributes in Table 4, Model 2, we see that child age and gender have no association with the likelihood of parents reporting that they received time from their children. Parent's numbers of children, however, are associated with the likelihood of receiving time from each child. Those with 2 children are less likely to receive time from each than those with one; those with three are even less likely; and parents with four 
or more children are the least likely to receive care from each child, about 15 percent less likely to receive time transfers from a given child than what is received by parents with only one. Of course, as with many of the results above, the marginal loss in likelihoods of receipt of time transfer per child are not outweighed by the cumulative effect of multiple children. In this model, greater wealth differentials between parents and children are not associated changes in the likelihood that parents report receiving time transfers from their children. Parents who liver further from their children tend to be less likely to receive time from them; about 1 percent less per 100 miles apart. Coresident parents are much more likely to receive time from their children, about 6 percent than non-coresident parents. In Model 3, we examine fixed effects on parent attributes. This model highlights that parents are less likely to receive time transfers from older adult children above 51 years old. In the fixed effects model, parents who are wealthier than their children are less likely to receive time from them. The distance effect is comparable in these models, but the coresidence effect is no longer significant.

We now look at the amount of time parents report receiving from their children, conditional on them receiving any (Table 4, Models 4 through 6). In both Models 4 and 5 we see a U-shaped pattern by parental birth cohort. Middle age parents in both models receive the least time from their children. Parent race and ethnicity is also significant in both models. Black parents report receiving more hundreds of additional hours of support from their children than White parents do. In eight hour workday terms, the race and ethnicity effect in Model 5 equates to the receipt of an additional 27 workdays for Black parents than White parents. Black parents who receive transfers report receiving about 1.5 times as many hours in total as White parents who receive transfers report receiving. Looking at child attributes (Model 5), only child gender is significant for the amount of transfers, with parents who receive transfers reporting receiving about 120 more hours from female children than from male children. In the fixed effects model (Model 6), however, these results differ: there are no significant differences between children of different genders. By contrast, parents who receive time transfers from their children report receiving the most hours from their older adult children who are at least 51 years in age. This is a very large effect, such that parents report receiving over three times as many transfers from older adult children than from young adult children. When looking at parental birth cohort by parental race and ethnicity interactions (Figure 3), we can see that racial and ethnic disparities in 
parental receipt of transfers appears to be growing among more recent parental birth cohorts compared to older cohorts.

\section{Parents Receiving Money from Their Children (Parent Reports)}

Table 5 is laid out in the same fashion as Tables 2 through 4, except its focus is on parental reports of their receipt of money transfers. It is worth noting that only a small proportion of parents report receiving money transfers from their children. Parents reported receipt of money from their children in only about 8 percent of parent-child dyads.

Looking at parental attributes in Models 1 and 2 of Table 5, we see that mothers are approximately 7 percent more likely than fathers to report receiving a transfer of time. The only other significant effect in terms of ascribed parental attributes is that Black parents report being approximately 5 percent to 7 percent and Hispanic parents about 3 percent to 5 percent more likely to receive a time transfer from their children than White parents. These effects are generally comparable between Models 1 and 2. There are few associations between parental receipt of money transfers from children and achieved parent attributes or child attributes. The only significant effect in these regards are that parents with four or more children are significantly less likely to receive money transfers from each than parents with only one child (Model 2). Indeed, this effect is so strong that a parent with 4 children $(0.056=4 \times(0.084-$ 0.070)) would be about two thirds as likely to receive a money transfer from at least one of them as a parent with only one child (0.084) under an independence assumption. We see no effects of child gender, child age group, parent/child wealth differential, geographic distance, or coresidence in the likelihood of receiving money transfers (Model 2). The fixed effects model (Model 3), however, reveals that parents who are relatively wealthier than their children are significantly less likely to report receiving a money transfer from them. Each decile change in the distribution of wealth differences between parents and children is associated with about a $1 / 2$ a percentage point reduction in the likelihood of the parent receiving a money transfer from the child in this model. The fixed effects model also surprisingly shows that coresident parents are less likely to receive a time transfer from their child.

Models 3 through 6 reveal in Table 5 no significant differences by achieved or ascribed parental characteristics, parent/child differentials, or child attributes in the likelihood of the parent receiving a money transfer from the child. Because we only run these models on parents 
who reported receiving at least some money from their children, and only about 8 percent of parents do so, these models all have small sample sizes, which probably leads to these null findings. Figure 4 shows some substantively interesting changes over parental birth cohort by race and ethnicity in the likelihood that parents receive monetary transfers from their children. More recent birth cohorts of Hispanic parents appear more likely to receive transfers than more recent birth cohorts of White parents, whereas the opposite tendency appears to hold among the oldest parental birth cohort, where Hispanic parents are less likely to receive transfers than White parents. Black parents in the older birth cohort were just as likely as White parents to receive money transfers, but in the more recent birth cohorts they are more likely to receive them. Among those who receive any such transfers, this figure also shows that differences between Black and White parents in the amounts received do not appear to change meaningfully across parental birth cohorts.

\section{Discussion}

We examined within-family transfers of time and money provided both to and from retirement aged older adults, those aged at least 50 years old in 2013. Drawing on unique and underutilized data from the PSID that measure dyadic transfer amounts between parents and children in the past year, we used multivariate regression techniques to consider racial and ethnic disparities in transfer rates, how differences manifest across a larger range of parental birth cohorts considered in prior studies, the role of parent gender, and how numbers of children affect parental likelihoods of giving to or receiving from each. We also examined child attributes and parent/child differences, including through fixed effects approaches at the parent level. Of particular interest were comparisons between parents with children of different genders and parents with different numbers of children who were to give or receive transfers of time and money, how parent/child wealth differentials played into likelihoods of giving and receiving transfers, and how the geographic embeddedness of family relationships alters giving likelihoods.

To summarize our results, we have constructed Table 6 (best viewed in color), which pools the conclusions we have drawn from several models together. In other words, this table is intended to summarize results presented in Tables 2 to 5, Appendix Table A1, and Figures 1 to 4. This table groups probabilities of transfers on the left, and the size of transferred amounts on the 
right. Within these groups, we subdivide the provision of transfers and the receipt of transfers. The rows of the table show the key independent variables analyzed throughout the article. Each cell in the table represents the conclusion we have drawn about the association of the independent variable indexed in the row and the focal outcome indexed by the column. For parent attributes, we draw our conclusions from the models that include both parent and child attributes (Models 2 and 5 in Tables 2 to 5). For child attributes and parent/child differences, we draw our conclusions from the fixed effects models (Models 3 and 6 in Tables 2 to 5). For the race and ethnicity by cohort interactions, we draw our conclusions from qualitative assessments of inter-cohort trends in Figures 1 to 4 . Because our models of amounts transferred are conducted on smaller samples only among those transferring, we prioritize discussing the probability of transfers and constrain our discussion of amounts to cases where the results for amounts differ from the results for probabilities.

Table 6 reveals an interesting pattern with respect to gender. It shows that giving transfers is largely genderless, but that receipt of transfers is highly gendered. There are no differences in the probability that mothers or fathers give to their children, and there are no differences in the probability that sons or daughters give to their parents. Female-headed households are more likely to receive time and money from their children than male-headed households, and daughters are more likely to receive time and money from their parents. This result is surprising given the extent to which prior literature on family roles has considered women to be "kin keepers” (Hagestad 1986; Spitze and Logan 1990) (Hagestad 1986, Spitze \& Logan 1990), who engage in more "network maintaining work” (Wellman 1984:17). Based on such arguments, one would expect that women provide more transfers, if not in terms of money perhaps in terms of time. However, our results suggest the opposite: no gender differences in the provision of transfers but women are more likely to receive them. Perhaps a reason for this finding is that women do engage in more discussion with family, providing emotional support (Wellman and Wortley 1990) and “expressive social capital” (Lin 1999), but they do not engage in the material dimensions of social support, what Lin (1999) calls "instrumental social capital”. Doing so, it may be that women receive more transfers from family as a form of exchange, where transfers function like payments for the work of providing emotional and expressive support. An alternative interpretation of these results is that family structure dominates parental 
receipt of transfers, because PSID is a household based survey where female parents are heads of households.

Another finding to emerge in Table 6 is the strong patterns by parental birth cohorts. We interpret some of these patterns as age effects, and others as cohort effects, but given the crosssectional nature of our data we cannot reliably distinguish between these two factors. Our results suggest that older parents are less likely to transfer time to their children but more likely to receive, which makes sense because older individuals are likely to be in poorer health. White/non-White racial and ethnic disparities in the parental provision of time transfers to children and the receipt of money transfers from children appear to be growing. Disparities in the likelihood of giving money appear to be shrinking. Looking at child ages, we see what appears to be a consistent pattern wherein older children are less likely to give or receive transfers than younger children.

The numbers of children strongly conditions parents' likelihood of giving to or receiving from each. Successively more children are associated with increasingly negative marginal likelihoods of transferring. However, we found that parents with more children have independently higher likelihoods of transferring because of the cumulative transfer probabilities across children. Parent/child wealth differences are negatively associated with the likelihood that parents who are relatively wealthier than their children receive both time and money transfers from their children. Parents with more money than their children, however, are more likely to give them money, a result that is to be expected based on supply and demand factors. Parents who live in the same house as their children are intriguingly more likely to give them money and less likely to receive money from them, but there is no association with time. This result contrasts with older work that suggested that coresidence plays an especially important role in social support stratification around the provision of free childcare and eldercare (Hofferth 1984; Hogan et al. 1990); perhaps overall declines in intergenerational and other forms of coresidence since then have altered the contexts of coresident families (Klinenberg 2012; Ruggles 2007). Among those living apart, distance demonstrates a clear negative association with the likelihood that parents give or receive time transfers, but no relationship with financial transfers. Clearly, spatial separation makes it more difficult for family to provide time to one another, but spatial separation may also fray bonds and lead to less knowledge about the types of help needed. It is interesting to note that spatially separated families appear neither more nor 
less likely to send money to one another. This result undercuts the notion that transfers of money and time in a given direction always trade off against one another. American internal migration and distance from family appears to have declined in recent decades, starting in the 1980s (Molloy, Smith, and Wozniak 2011, 2014). This change over time may lead to greater withinfamily transfers of time that help to alleviate burdens of care.

The combination of these effects increase our understanding a substantial amount of gaps in financial exchange between Blacks, Hispanics, and Whites, and a moderate amount of time exchange gaps, both for parental resource giving and receipt. The clearest demonstration of the explanatory power of these factors is seen in model 2 of Table 3, where the Black-White gap in the probability of parents giving money to children is reduced by more than half as a result of adjusting for child demographic, socioeconomic, and spatial characteristics along with number of children. The Hispanic-White gap is similarly reduced by 36 percent in this model. Nor do these effects stop at whether funds are given - they also influence amounts given conditional on giving status. Accounting for these factors reduces the Black-White gap in this outcome among parents who gave to their children by more than $\$ 500$ a year (from $\$ 2297$ to $\$ 1791$ ). A more complex pattern is observed for parental receipt of funds - accounting for these factors actually increases the Black-White gap by 24 percent and the Hispanic-White gap by 51 percent. Turning to amounts received by parents, however, Black parents actually receive more money on average than White parents, and this difference is reduced by 29 percent when accounting for these same factors. In contrast, more modest mediating effects are observed for time exchange, where these factors account for 15 percent of the Black-White gap in giving status and 10 percent of the amount of time given, a negligible change on the probability of receiving time and a 7 percent reduction in the conditional amount of time received. For Hispanics, similar patterns are observed for giving/receiving status, as these factors account for 9 percent of the Hispanic-White gap in parental time given and increase the same gap in time received from children by 7 percent. All together, we conclude that numbers of children and child characteristics are a very important factor in parent-child financial exchange, but a more limited one in time exchange.

Our study contains a number of limitations. First, we do not study those with no kin, because one must have kin to be at risk of transferring with them. Older adults without kin are thought to comprise approximately 7 percent of the population above 50 years old in recent years (Margolis and Verdery 2017). The prevalence of this phenomenon is generally comparable 
between White and non-White older adults. Older adults without living family are at elevated risk of social isolation, and tend to be more financially precarious and in worse health than those with living family members (Margolis and Verdery 2017). Recent demographic projections hold that the size of the population of older adults without living family members will grow substantially in the coming decades, with especially notable increases in the prevalence of this family form for Black Americans (Verdery and Margolis 2017). We also do not study nonfamilial transfers. While we know of no studies that have looked at levels of transfers with nonfamily members for retirees, recent work has examined access to social support that could provide transfers of services or money through both family and non-family sources (Verdery and Campbell 2017). This work shows that only approximately two-thirds of those who report no access to social support through family have any access at all to it they would need through friends and only about one-fifth of those with no access to support through family report having all the access to support they need through friends (Verdery and Campbell 2017).

\section{Conclusion}

Within-family transfers of time and money are an important aspect of life for retirement aged adults. We find that kin availability, wealth differentials, geographic proximity, and gender all play meaningful roles in structuring the provision and receipt of transfers from adults 50 and above in 2013. Our results also point to large racial and ethnic disparities, wherein non-White older adults are less likely to give either time or money transfers to their children than White older adults. Non-White older adults are also less likely to receive time transfers from their children, but they are more likely to receive money transfers from them. However, among nonWhite older adults who engage in transfers, the receipt and provision of time is larger than the amount received and provided by White individuals who engage in transfers. Parents with more children are less likely to provide or receive transfers from each, but they are more likely to provide and receive transfers overall because of the cumulative effects of having multiple children. Geographic distance reduces the likelihood of providing and receiving time transfers, and, while female children and parents are more likely to receive transfers, we find no evidence of gender differences in the provision of transfers. Parents with more wealth than their children are more likely to give them money, and are less likely to receive either time or money from them. In general, racial and ethnic disparities in transfers appear to be growing across successive 
parental birth cohorts. However, parental provision of money to their children does not appear to be growing across parent birth cohorts, which may mean that the effects of transfers on the racial wealth gap (McKernan et al. 2014) may be shrinking. Further research on these topics could help to shed light on the policy challenges associated with these changing disparities in transfer rates. 


\section{References}

Barro, Robert J. 1974. “Are Government Bonds Net Wealth?” The Journal of Political Economy 82(6): 1095-1117.

Becker, Gary. 1974. A Theory of Social Interactions. Working Paper 42. Cambridge, MA: National Bureau of Economic Research.

Bernheim, B. Douglas, Andrei Shleifer, and Lawrence H. Summers. 1985. “The Strategic Bequest Motive.” The Journal of Political Economy 93(6): 1045-1076.

Berry, Brent. 2006. "Friends for Better or for Worse: Interracial Friendship in the United States as Seen through Wedding Party Photos.” Demography 43(3): 491-510.

Cooney, Teresa M. and Peter Uhlenberg. 1992. "Support from Parents over the Life Course: The Adult Child’s Perspective.” Social Forces 71(1): 63-84.

Cox, Donald. 1987. “Motives for Private Income Transfers.” The Journal of Political Economy 95(3): 508-546.

Cox, Donald, Bruce E. Hansen, and Emmanuel Jimenez. 2004. "How Responsive Are Private Transfers to Income? Evidence from a Laissez-Faire Economy.” Journal of Public Economics 88(9-10): 2193-2219.

Cox, Donald and Mark R. Rank. 1992. "Inter-Vivos Transfers and Intergenerational Exchange.” The Review of Economics and Statistics 74(2): 305-314.

Daw, Jonathan and Ashton Verdery. 2014. "Beyond Household Walls: The Spatial Structure of American Kinship Networks.” Boston, MA. Available at: http://paa2014.princeton.edu/abstracts/142872.

Daw, Jonathan, Ashton Verdery, and Rachel Margolis. 2016. “Kin Count(s): Educational and Racial Differences in Extended Kinship in the United States.” Population and Development Review 42(3): 491-517.

Duffy, Denise and Narayan Sastry. 2012. "An Assessment of the National Representativeness of Children in the 2007 Panel Study of Income Dynamics.” PSID Technical Series Paper 12-01. Ann Arbor, MI: Survey Research Center, Institute for Social Research, University of Michigan

Edin, Kathryn and Laura Lein. 1997. Making Ends Meet: How Single Mothers Survive Welfare and Low-Wage Work. New York, NY: Russell Sage Foundation. 
Fingerman, Karen L., Lindsay M. Pitzer, Wai Chan, Kira Birditt, Melissa M. Franks, and Steven Zarit. 2010. "Who Gets What and Why? Help Middle-Aged Adults Provide to Parents and Grown Children.” The Journals of Gerontology Series B: Psychological Sciences and Social Sciences 66B(1): 87-98.

Fingerman, Karen L., Kyungmin Kim, Eden M. Davis, Frank F. Furstenberg Jr., Kira S. Birditt, and Steven H. Zarit. 2015. “'I'll Give You the World': Socioeconomic Differences in Parental Support of Adult Children.” Journal of Marriage and Family 77(4): 844-865.

Gale, William G. and John Karl Scholz. 1994. "Intergenerational Transfers and the Accumulation of Wealth.” The Journal of Economic Perspectives 8(4): 145-160.

Gaugler, Joseph E., Sue Duval, Keith A. Anderson, and Robert L. Kane. 2007. "Predicting Nursing Home Admission in the U.S: A Meta-Analysis.” BMC Geriatrics 7:13.

Gordon, Roger H. and Hal R. Varian. 1988. “Intergenerational Risk Sharing.” Journal of Public Economics 37(2): 185-202.

Granovetter, Mark. 1985. "Economic Action and Social Structure: The Problem of Embeddedness.” American Journal of Sociology 91(3): 481-510.

Hagestad, Gunhild O. 1986. “The Family: Women and Grandparents as Kin-Keepers.” In Our Aging Society: Paradox and Promise, edited by A. Pifer and L. Bronte, 141-161. New York, NY: W. W. Norton.

Hao, Lingxin. 1996. "Family Structure, Private Transfers, and the Economic Well-Being of Families with Children.” Social Forces 75(1): 269-292.

Hofferth, Sandra L. 1984. “Kin Networks, Race, and Family Structure.” Journal of Marriage and the Family 46(4): 791-806.

Hogan, Dennis P., David J. Eggebeen, and Clifford C. Clogg. 1993. "The Structure of Intergenerational Exchanges in American Families.” American Journal of Sociology 98(6): 1428-1458.

Hogan, Dennis P., Ling-Xin Hao, and William L. Parish. 1990. "Race, Kin Networks, and Assistance to Mother-Headed Families.” Social Forces 68(3): 797-812.

Joulfaian, David. 2014. Intergenerational Transfers Under an Uncertain Estate Tax. Rochester, NY: Social Science Research Network. Available at: http://papers.ssrn.com/abstract=2489245.

Klinenberg, Eric. 2012. Going Solo: The Extraordinary Rise and Surprising Appeal of Living Alone. London, England: Penguin Books. 
Lee, Yean-Ju and Isik A. Aytac. 1998. "Intergenerational Financial Support among Whites, African Americans, and Latinos.” Journal of Marriage and Family 60(2): 426-441.

Lin, Nan. 1999. "Building a Network Theory of Social Capital.” Connections 22(1): 28-51.

Luppa, Melanie, T. Luck, S. Weyerer, H. H. König, E. Brähler, S. G. Riedel-Heller. 2009. "Prediction of Institutionalization in the Elderly. A Systematic Review." Age and Ageing 39(1): 31-38.

Lutz, Wolfgang. 2013. "Demographic Metabolism: A Predictive Theory of Socioeconomic Change.” Population and Development Review 38(s1):283-301.

Manning, Wendy D. and Pamela J. Smock. 1995. "Why Marry? Race and the Transition to Marriage among Cohabitors.” Demography 32(4): 509-520.

Margolis, Rachel and Ashton M. Verdery. 2017. "Older Adults Without Close Kin in the United States.” The Journals of Gerontology: Series B. Available at: https://academic.oup.com/psychsocgerontology/article/doi/10.1093/geronb/gbx068/3860 151/Older-Adults-Without-Close-Kin-in-the-United.

McGarry, Kathleen. 2012. "Dynamic Aspects of Family Transfers." Working Paper 18446. Cambridge, MA: National Bureau of Economic Research.

McGarry, Kathleen and Robert F. Schoeni. 1995. "Transfer Behavior in the Health and Retirement Study: Measurement and the Redistribution of Resources within the Family.” Journal of Human Resources 30: S184-226.

McKernan, Signe-Mary, Caroline Ratcliffe, Margaret Simms, and Sisi Zhang. 2014. "Do Racial Disparities in Private Transfers Help Explain the Racial Wealth Gap? New Evidence From Longitudinal Data.” Demography 51(3): 949-974.

Modigliani, Franco. 1988. "The Role of Intergenerational Transfers and Life Cycle Saving in the Accumulation of Wealth.” The Journal of Economic Perspectives 2(2): 15-40.

Molloy, Raven, Christopher L. Smith, and Abigail Wozniak. 2011. "Internal Migration in the United States.” The Journal of Economic Perspectives 25(3): 173-196.

Molloy, Raven, Christopher L. Smith, and Abigail K. Wozniak. 2014. "Declining Migration within the US: The Role of the Labor Market." Working Paper 20065. Cambridge, MA: National Bureau of Economic Research.

Rogers, Richard G., Robert A. Hummer, and Charles B. Nam. 1999. Living and Dying in the USA: Behavioral, Health, and Social Differentials of Adult Mortality. San Diego, CA: Academic Press. 
Rossi, Peter Peter Henry. 1990. Of Human Bonding: Parent-Child Relations Across the Life Course. Abington, UK: Routledge.

Ruggles, Steven. 2007. "The Decline of Intergenerational Coresidence in the United States, 1850 to 2000.” American Sociological Review 72(6): 964-989.

Sarkisian, Natalia, Mariana Gerena, and Naomi Gerstel. 2007. "Extended Family Integration among Euro and Mexican Americans: Ethnicity, Gender, and Class.” Journal of Marriage and Family 69(1): 40-54.

Sarkisian, Natalia and Naomi Gerstel. 2004. "Kin Support among Blacks and Whites: Race and Family Organization.” American Sociological Review 69(6): 812-837.

Schoeni, Robert F., Suzanne M. Bianchi, V.Joseph Hotz, Judith A. Seltzer, and Emily E. Wiemers. 2015. "Intergenerational Transfers and Rosters of the Extended Family: A New Substudy of the Panel Study of Income Dynamics.” Longitudinal and Life Course Studies 6(3): 319-330.

Spitze, Glenna and John Logan. 1990. "Sons, Daughters, and Intergenerational Social Support.” Journal of Marriage and the Family 52(2): 420-430.

St. John, Craig. 1982. "Race Differences in Age at First Birth and the Pace of Subsequent Fertility: Implications for the Minority Group Status Hypothesis.” Demography 19(3): 301-314.

Stack, Carol B. 1975. All Our Kin. New York, NY: Basic Books.

Stein, Catherine H., Virginia A. Wemmerus, Marcia Ward, Michelle E. Gaines, Andrew L. Freeberg and Thomas C. Jewell. 1998. “'Because They're My Parents': An Intergenerational Study of Felt Obligation and Parental Caregiving.” Journal of Marriage and the Family 60(3): 611-622.

Umberson, Debra, Julie Skalamera Olson, Robert Crosnoe, Hui Liu, Tetyana Pudrovska, and Rachel Donnelly. 2017. "Death of Family Members as an Overlooked Source of Racial Disadvantage in the United States.” Proceedings of the National Academy of Sciences 114(5): 915-920.

Verdery, Ashton M. 2015. "Links Between Demographic and Kinship Transitions.” Population and Development Review 41(3): 465-484.

Verdery, Ashton M. and Colin Campbell. 2017. "Social Capital in America: Stability in Social Support Networks over Two Decades."

Verdery, Ashton M. and Rachel Margolis. 2017. "Projections of Black and White Older Adults without Living Kin in the United States, 2015-2060.” 
Vincenty, Thaddeus. 1975. "Direct and Inverse Solutions of Geodesics on the Ellipsoid with Application of Nested Equations.” Survey Review 23(176): 88-93.

Wellman, Barry. 1984. Domestic Work, Paid Work and Network. Toronto, Ontario: Centre for Urban and Community Studies, University of Toronto.

Wellman, Barry and Scot Wortley. 1990. "Different Strokes from Different Folks: Community Ties and Social Support.” American Journal of Sociology 96(3): 558-588.

Wilhelm, Mark O. 1996. "Bequest Behavior and the Effect of Heirs’ Earnings: Testing the Altruistic Model of Bequests.” The American Economic Review 86(4): 874-892. 
Table 1. Descriptive Statistics

\begin{tabular}{lccc}
\hline Variables & Observations & Mean/proportion & SD \\
\hline Outcome & & & \\
Parent gives time & 5,204 & 0.32 & \\
$\quad$ amount given if any & 1,669 & 366.07 & 897.96 \\
Parent receives time & 5,204 & 0.25 & \\
$\quad$ amount received if any & 1,300 & 323.69 & 800.31 \\
Parent gives money & 5,204 & 0.31 & \\
$\quad$ amount given if any & 1,639 & $3,084.05$ & $7,399.72$ \\
Parent receives money & 5,204 & 0.09 & \\
$\quad$ amount received if any & 464 & 595.09 & 964.14 \\
Parent is & & & \\
Female & 5,204 & 0.34 & \\
Born 1935-44 & 5,204 & 0.13 & \\
Born 1945-54 & 5,204 & 0.33 & \\
Born 1955-63 & 5,204 & 0.43 & \\
Black & 5,204 & 0.34 & \\
Hispanic & 5,204 & 0.07 & \\
Other race & 5,204 & 0.02 & \\
Child is & & & \\
Age 36-50 & 5,204 & 0.28 & \\
Age 51+ & 5,204 & 0.13 & \\
Female & 5,204 & 0.51 & \\
Parent has & & & \\
2 children & 5,204 & 0.27 & \\
3 children & 5,204 & 0.27 & \\
4+ children & 5,204 & 0.40 & \\
Differences & & & \\
Decile of wealth difference & 5,204 & 5.03 & 2.90 \\
Miles apart $\times 100$ & 5,204 & 1.38 & 3.81 \\
Same HH & 5,204 & 0.30 & 0.46 \\
\hline
\end{tabular}


Table 2. Models of Parent Reports of Parents Giving Time to Children, Whether Any Given and Amount, If Any

\begin{tabular}{|c|c|c|c|c|c|c|}
\hline \multirow[b]{2}{*}{ Variables } & \multicolumn{3}{|c|}{ Whether time given } & \multicolumn{3}{|c|}{ Amount given if any } \\
\hline & (1) & (2) & (3) & (4) & (5) & (6) \\
\hline \multicolumn{7}{|l|}{ Parent is } \\
\hline Male & ref & ref & & ref & ref & \\
\hline Female & 0.00457 & 0.00901 & & 95.17 & 82.80 & \\
\hline Born 1914-34 & ref & ref & & ref & ref & \\
\hline Born 1935-44 & $0.131 * *$ & $0.0747 * *$ & & $295.1^{* *}$ & $181.8+$ & \\
\hline Born 1945-54 & $0.312^{* *}$ & $0.153^{* *}$ & & $167.2^{*}$ & -17.86 & \\
\hline Born 1955-63 & $0.377 * *$ & $0.167^{* *}$ & & $207.5^{* *}$ & -52.37 & \\
\hline White & ref & ref & & ref & ref & \\
\hline Black & $-0.104 * *$ & $-0.0880 * *$ & & $247.0^{* *}$ & $221.4^{* *}$ & \\
\hline Hispanic & $-0.204 * *$ & $-0.186 * *$ & & & & \\
\hline Other race & $-0.156^{* *}$ & $-0.159 * *$ & & & & \\
\hline \multicolumn{7}{|l|}{ Child is } \\
\hline Age 16-35 & & ref & ref & & ref & ref \\
\hline Age 36-50 & & $-0.0776 * *$ & $-0.0507 *$ & & -47.95 & 116.6 \\
\hline Age 51+ & & $-0.157^{* *}$ & $-0.124^{* *}$ & & $-274.8+$ & -20.26 \\
\hline Male & & ref & ref & & ref & ref \\
\hline Female & & $0.0637 * *$ & $0.0526 * *$ & & 42.52 & 18.98 \\
\hline \multicolumn{7}{|l|}{ Parent has } \\
\hline 1 child & & ref & & & ref & \\
\hline 2 children & & $-0.0946 * *$ & & & -160.0 & \\
\hline 3 children & & $-0.143 * *$ & & & $-173.4+$ & \\
\hline 4+ children & & $-0.209 * *$ & & & -76.65 & \\
\hline \multicolumn{7}{|l|}{ Differences } \\
\hline Decile of wealth & & $0.00700 * *$ & 0.000587 & & -12.18 & $-29.60+$ \\
\hline Miles apart $\times 100$ & & $-0.0106^{* *}$ & - & & -6.621 & 10.89 \\
\hline Same HH & & $0.0471^{*}$ & -0.0188 & & $134.9+$ & $192.0 *$ \\
\hline Constant & $0.0908 * *$ & $0.355^{* *}$ & $0.341 * *$ & 58.63 & $425.9 *$ & $403.9 * *$ \\
\hline Observations & 5,204 & 5,204 & 5,204 & 1,572 & 1,572 & 1,572 \\
\hline Number of Parents & & & 2,495 & & & 996 \\
\hline R-squared & 0.078 & 0.119 & 0.022 & 0.028 & 0.043 & 0.018 \\
\hline
\end{tabular}

Notes: Robust standard errors not shown; ${ }^{* *} \mathrm{p}<0.01,{ }^{*} \mathrm{p}<0.05,+\mathrm{p}<0.1$; ref indicates this variable is a reference category in this model; wealth differences computed as the decile of parent wealth minus child wealth; Models 4 through 6 exclude Hispanic and Other race respondents. 
Table 3. Models of Parent Reports of Parents Giving Money to Children, Whether Any Given and Amount, If Any

\begin{tabular}{|c|c|c|c|c|c|c|}
\hline \multirow[b]{2}{*}{ Variables } & \multicolumn{3}{|c|}{ Whether money given } & \multicolumn{3}{|c|}{ Amount given if any } \\
\hline & (1) & (2) & (3) & (4) & (5) & (6) \\
\hline \multicolumn{7}{|l|}{ Parent is } \\
\hline Male & ref & ref & & ref & ref & \\
\hline Female & $-0.0649 * *$ & $-0.0377+$ & & -457.8 & -292.1 & \\
\hline Born 1914-34 & ref & ref & & ref & ref & \\
\hline Born 1935-44 & -0.00497 & -0.0412 & & 368.0 & 1,042 & \\
\hline Born 1945-54 & $0.122 * *$ & -0.00465 & & -908.4 & -40.65 & \\
\hline Born 1955-63 & $0.154^{* *}$ & -0.0277 & & -699.7 & 18.22 & \\
\hline White & ref & ref & & ref & ref & \\
\hline Black & $-0.111^{* *}$ & $-0.0492^{*}$ & & $2,297 * *$ & $1,791^{* *}$ & \\
\hline Hispanic & $-0.177 * *$ & $-0.114^{* *}$ & & & & \\
\hline Other race & -0.0193 & -0.0253 & & & & \\
\hline \multicolumn{7}{|l|}{ Child is } \\
\hline Age 16-35 & & ref & ref & & ref & ref \\
\hline Age $36-50$ & & $\begin{array}{c}- \\
0.0765 * *\end{array}$ & $-0.0340+$ & & 192.2 & -137.8 \\
\hline Age 51+ & & $-0.0708^{*}$ & $-0.0740^{*}$ & & 2,668 & $-2,598 *$ \\
\hline Male & & ref & ref & & ref & ref \\
\hline Female & & 0.00449 & $0.0290 * *$ & & -356.0 & -313.1 \\
\hline \multicolumn{7}{|l|}{ Parent has } \\
\hline 1 child & & ref & & & ref & \\
\hline 2 children & & $-0.0675^{*}$ & & & -868.5 & \\
\hline 3 children & & $-0.157 * *$ & & & $-1,562$ & \\
\hline 4+ children & & $-0.258 * *$ & & & $-2,171^{*}$ & \\
\hline \multicolumn{7}{|l|}{ Differences } \\
\hline $\begin{array}{l}\text { Decile of wealth } \\
\text { difference }\end{array}$ & & $0.0248 * *$ & $0.00887 * *$ & & $317.7^{* *}$ & -94.38 \\
\hline Miles apart $\times 100$ & & $0.00456 *$ & -0.00278 & & $-87.27+$ & 18.30 \\
\hline Same HH & & $0.115^{* *}$ & $0.0566^{* *}$ & & $1,510^{* *}$ & 11.59 \\
\hline Constant & $0.283^{* *}$ & $0.399 * *$ & $0.262 * *$ & $4,545^{*}$ & 2,558 & $4,075 * *$ \\
\hline Observations & 5,204 & 5,204 & 5,204 & 1,529 & 1,529 & 1,529 \\
\hline Number of Parents & & & 2,495 & & & 952 \\
\hline R-squared & 0.041 & 0.111 & 0.017 & 0.027 & 0.055 & 0.016 \\
\hline
\end{tabular}

Notes: Robust standard errors not shown; ${ }^{* *} \mathrm{p}<0.01,{ }^{*} \mathrm{p}<0.05,+\mathrm{p}<0.1$; ref indicates this variable is a reference category in this model; wealth differences computed as the decile of parent wealth minus child wealth; Models 4 through 6 exclude Hispanic and Other race respondents. 
Table 4. Models of Parent Reports of Parents Receiving Time from Children, Whether Any Received and Amount, If Any

\begin{tabular}{|c|c|c|c|c|c|c|}
\hline \multirow[b]{2}{*}{ Variables } & \multicolumn{3}{|c|}{ Whether time received } & \multicolumn{3}{|c|}{ Amount received if any } \\
\hline & (1) & (2) & (3) & (4) & (5) & (6) \\
\hline \multicolumn{7}{|l|}{ Parent is } \\
\hline Male & ref & ref & & ref & ref & \\
\hline Female & $0.153^{* *}$ & $0.143 * *$ & & 55.80 & 25.90 & \\
\hline Born 1914-34 & ref & ref & & ref & ref & \\
\hline Born 1935-44 & $-0.104 * *$ & $-0.116^{* *}$ & & $-263.2 *$ & -174.7 & \\
\hline Born 1945-54 & $-0.0616^{*}$ & $-0.110 * *$ & & $\begin{array}{c}- \\
415.1^{* *}\end{array}$ & $\begin{array}{c}- \\
279.9 * *\end{array}$ & \\
\hline Born 1955-63 & 0.000722 & $-0.0704+$ & & $\stackrel{-}{355.5^{* *}}$ & $-232.5+$ & \\
\hline White & ref & ref & & ref & ref & \\
\hline Black & $-0.0532 * *$ & $-0.0541 * *$ & & $236.3^{* *}$ & $219.2^{* *}$ & \\
\hline Hispanic & $-0.0832 * *$ & $-0.0891 * *$ & & & & \\
\hline Other race & 0.0128 & 0.000246 & & & & \\
\hline \multicolumn{7}{|l|}{ Child is } \\
\hline Age 16-35 & & ref & ref & & ref & ref \\
\hline Age 36-50 & & 0.0134 & -0.0188 & & 60.80 & 153.3 \\
\hline Age 51+ & & -0.0179 & $-0.105^{* *}$ & & 204.7 & $411.2^{*}$ \\
\hline Male & & ref & ref & & ref & ref \\
\hline Female & & 0.000700 & 0.00698 & & $123.6^{* *}$ & 63.48 \\
\hline \multicolumn{7}{|l|}{ Parent has } \\
\hline 1 child & & ref & & & ref & \\
\hline 2 children & & $-0.0870^{* *}$ & & & -128.1 & \\
\hline 3 children & & $-0.107^{* *}$ & & & $-197.7^{*}$ & \\
\hline 4+ children & & $-0.151 * *$ & & & -118.7 & \\
\hline \multicolumn{7}{|l|}{ Differences } \\
\hline $\begin{array}{l}\text { Decile of wealth } \\
\text { difference }\end{array}$ & & -0.00309 & $-0.00594 *$ & & -9.742 & -19.49 \\
\hline Miles apart $\times 100$ & & $-0.0102 * *$ & $\begin{array}{c}- \\
0.00899 * *\end{array}$ & & -3.202 & 0.411 \\
\hline Same HH & & $0.0596 * *$ & 0.0247 & & 104.2 & -18.73 \\
\hline Constant & $0.254^{* *}$ & $0.430 * *$ & $0.300^{* *}$ & $508.6^{* *}$ & $460.2 * *$ & $280.5^{* *}$ \\
\hline Observations & 5,204 & 5,204 & 5,204 & 1,209 & 1,209 & 1,209 \\
\hline Number of Parents & & & 2,495 & & & 747 \\
\hline R-squared & 0.036 & 0.059 & 0.019 & 0.053 & 0.071 & 0.022 \\
\hline
\end{tabular}

Notes: Robust standard errors not shown; ${ }^{* *} \mathrm{p}<0.01,{ }^{*} \mathrm{p}<0.05,+\mathrm{p}<0.1$; ref indicates this variable is a reference category in this model; wealth differences computed as the decile of parent wealth minus child wealth; Models 4 through 6 exclude Hispanic and Other race respondents. 
Table 5. Models of Parent Reports of Parents Receiving Money from Children, Whether Any Received and Amount, If Any

\begin{tabular}{|c|c|c|c|c|c|c|}
\hline \multirow[b]{2}{*}{ Variables } & \multicolumn{3}{|c|}{ Whether money received } & \multicolumn{3}{|c|}{ Amount received if any } \\
\hline & (1) & (2) & (3) & (4) & (5) & (6) \\
\hline \multicolumn{7}{|l|}{ Parent is } \\
\hline Male & ref & ref & & ref & ref & \\
\hline Female & $0.0725^{* *}$ & $0.0703^{* *}$ & & 129.6 & 128.5 & \\
\hline Born 1914-34 & ref & ref & & ref & ref & \\
\hline Born 1935-44 & 0.0126 & -0.00645 & & 48.45 & -72.36 & \\
\hline Born 1945-54 & 0.0201 & -0.0121 & & 86.51 & -81.79 & \\
\hline Born 1955-63 & 0.00249 & -0.0251 & & 159.6 & -14.15 & \\
\hline White & ref & ref & & ref & ref & \\
\hline Black & $0.0527 * *$ & $0.0654 * *$ & & 130.5 & 93.01 & \\
\hline Hispanic & 0.0314 & $0.0475^{*}$ & & & & \\
\hline Other race & 0.0423 & 0.0464 & & & & \\
\hline \multicolumn{7}{|l|}{ Child is } \\
\hline Age 16-35 & & ref & ref & & ref & ref \\
\hline Age $36-50$ & & 0.00948 & 0.00423 & & 39.25 & -13.45 \\
\hline Age 51+ & & -0.0229 & -0.000205 & & -295.1 & -390.5 \\
\hline Male & & ref & ref & & ref & ref \\
\hline Female & & $0.0136+$ & 0.00678 & & -20.70 & 4.667 \\
\hline \multicolumn{7}{|l|}{ Parent has } \\
\hline 1 child & & ref & & & ref & \\
\hline 2 children & & -0.0251 & & & -67.22 & \\
\hline 3 children & & -0.0275 & & & -52.68 & \\
\hline 4+ children & & $-0.0695 * *$ & & & 157.9 & \\
\hline \multicolumn{7}{|l|}{ Differences } \\
\hline $\begin{array}{l}\text { Decile of wealth } \\
\text { difference }\end{array}$ & & 0.00116 & $\begin{array}{c}- \\
0.00555^{* *}\end{array}$ & & -13.65 & 20.60 \\
\hline Miles apart $\times 100$ & & 0.00206 & 0.000974 & & 9.283 & 0.463 \\
\hline Same HH & & -0.00926 & $-0.0296 * *$ & & 143.1 & 80.83 \\
\hline Constant & $0.0338+$ & $0.0835^{*}$ & $0.120 * *$ & $319.8^{* *}$ & $526.8 *$ & $500.3 *$ \\
\hline Observations & 5,204 & 5,204 & 5,204 & 422 & 422 & 422 \\
\hline Number of Parents & & & 2,495 & & & 283 \\
\hline R-squared & 0.028 & 0.037 & 0.007 & 0.022 & 0.045 & 0.022 \\
\hline
\end{tabular}

Notes: Robust standard errors not shown; ${ }^{* *} \mathrm{p}<0.01,{ }^{*} \mathrm{p}<0.05,+\mathrm{p}<0.1$; ref indicates this variable is a reference category in this model; wealth differences computed as the decile of parent wealth minus child wealth; Models 4 through 6 exclude Hispanic and Other race respondents. 
Table 6. Summary of Results across Models

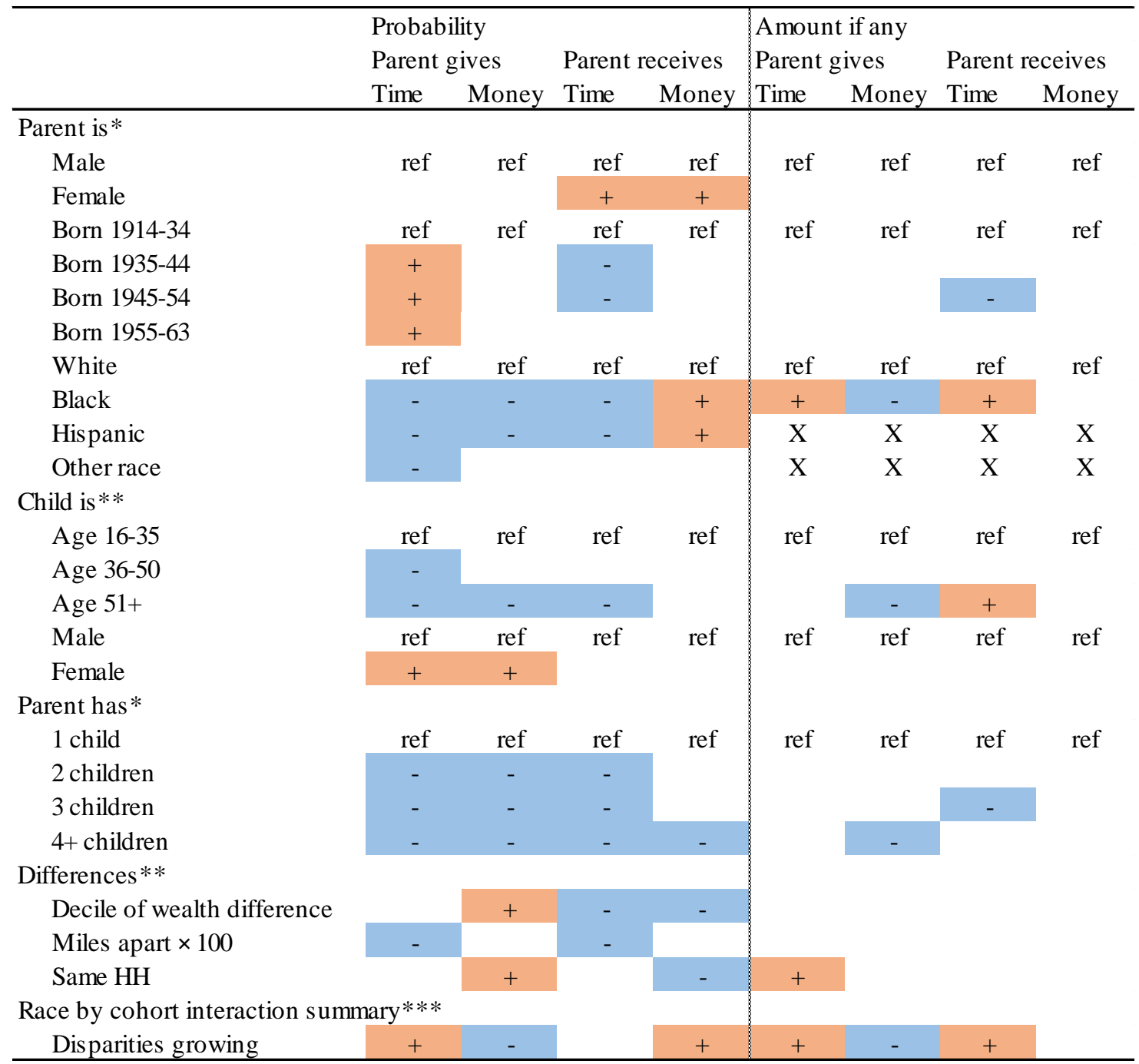

Notes: * results summarized from Models 2 and 5; ** results summarized from Models 3 and 6; *** results summarized from patterns of White/non-White disparities across older to more recent birth cohorts presented in Figures 1 to 4, where positive associations indicate disparities are growing and negative associations indicate they are shrinking; red highlighted cells with plus symbols indicate a significant positive deviation from the reference group and blue highlighted cells with minus symbols indicate a significant negative deviation from the reference group; cells with $\mathrm{X}$ in them are used to indicate that we did not model other Hispanic of Other race groups in the analyses of amounts transferred. 
Figure 1. Predicted Values from Parent Birth Cohort by Parent Race Interactions of Parent Reports of Parents Giving Time to Children, Whether Any Given and Amount, If Any
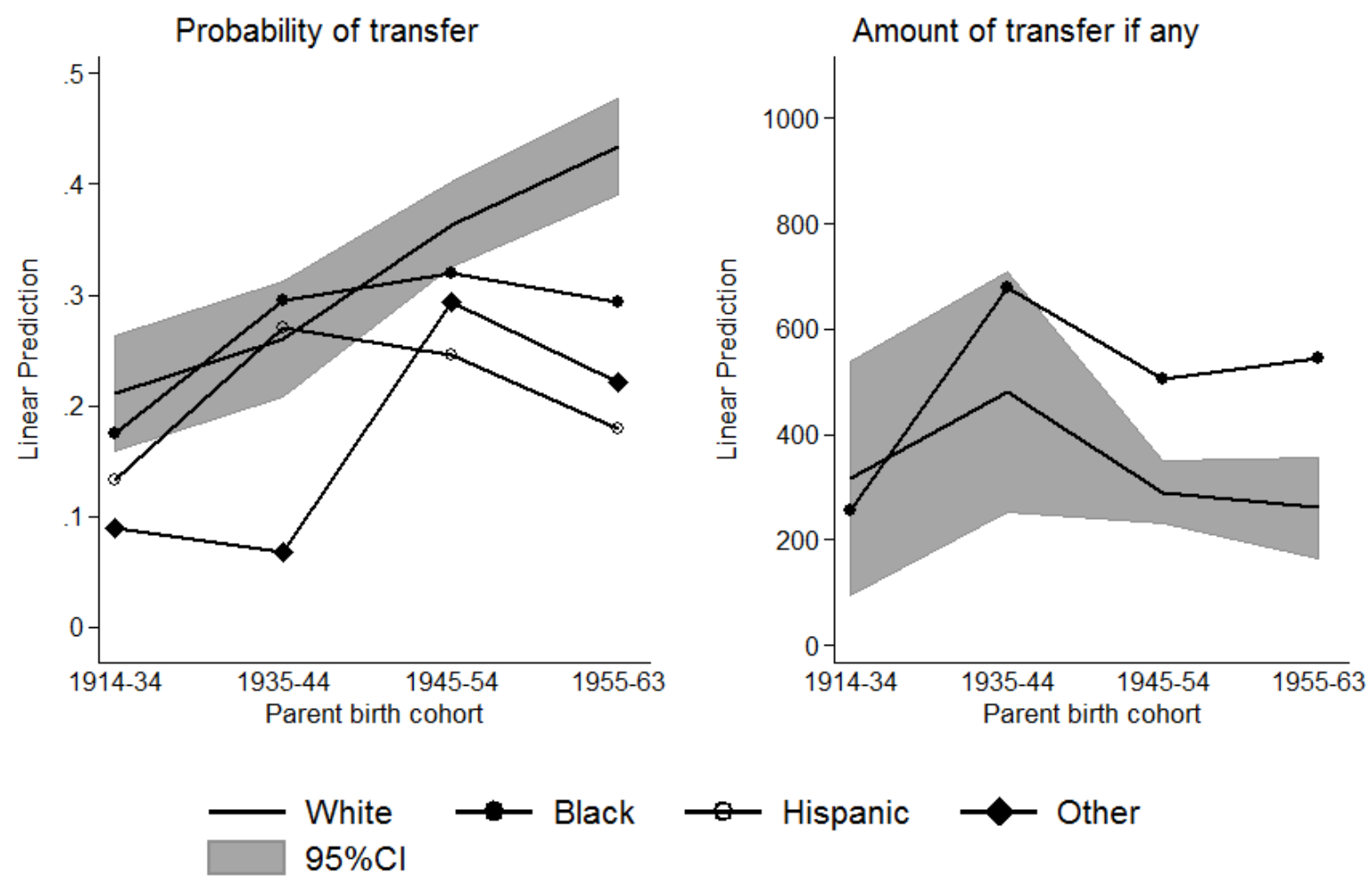

Note: Full regression results are available in Appendix Table A1, Models 1 (probability) and 5 (amount). Models of amounts exclude Hispanic and Other race respondents. 
Figure 2. Predicted Values from Parent Birth Cohort by Parent Race Interactions of Parent Reports of Parents Giving Money to Children, Whether Any Given and Amount, If Any
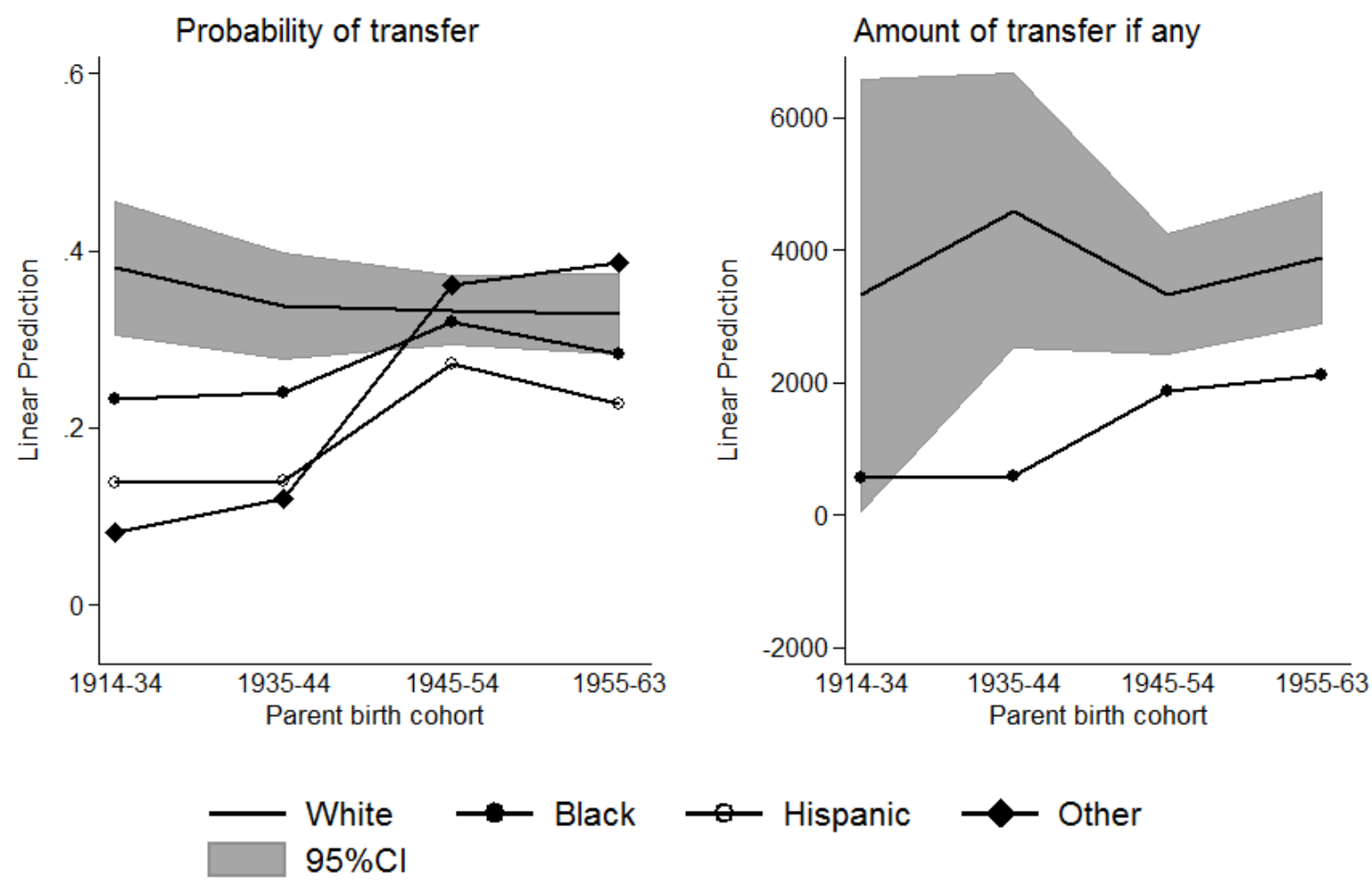

Note: Full regression results are available in Appendix Table A1, Models 2 (probability) and 6 (amount). Models of amounts exclude Hispanic and Other race respondents. 
Figure 3. Predicted Values from Parent Birth Cohort by Parent Race Interactions of Parent Reports of Parents Receiving Time from Children, Whether Any Received and Amount, If Any

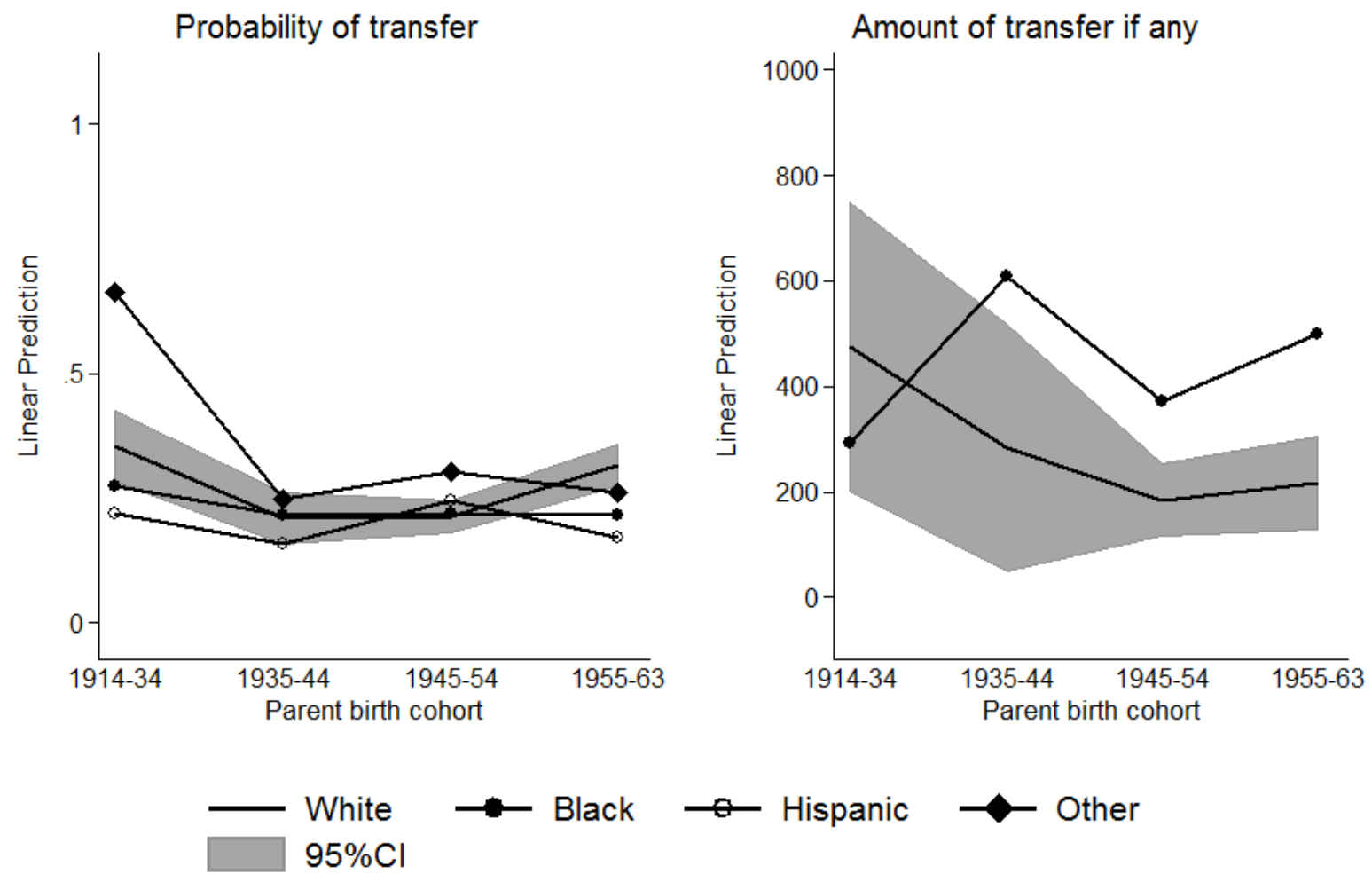

Note: Full regression results are available in Appendix Table A1, Models 3 (probability) and 7 (amount). Models of amounts exclude Hispanic and Other race respondents. 
Figure 4. Predicted Values from Parent Birth Cohort by Parent Race Interactions of Parent Reports of Parents Receiving Money from Children, Whether Any Received and Amount, If Any
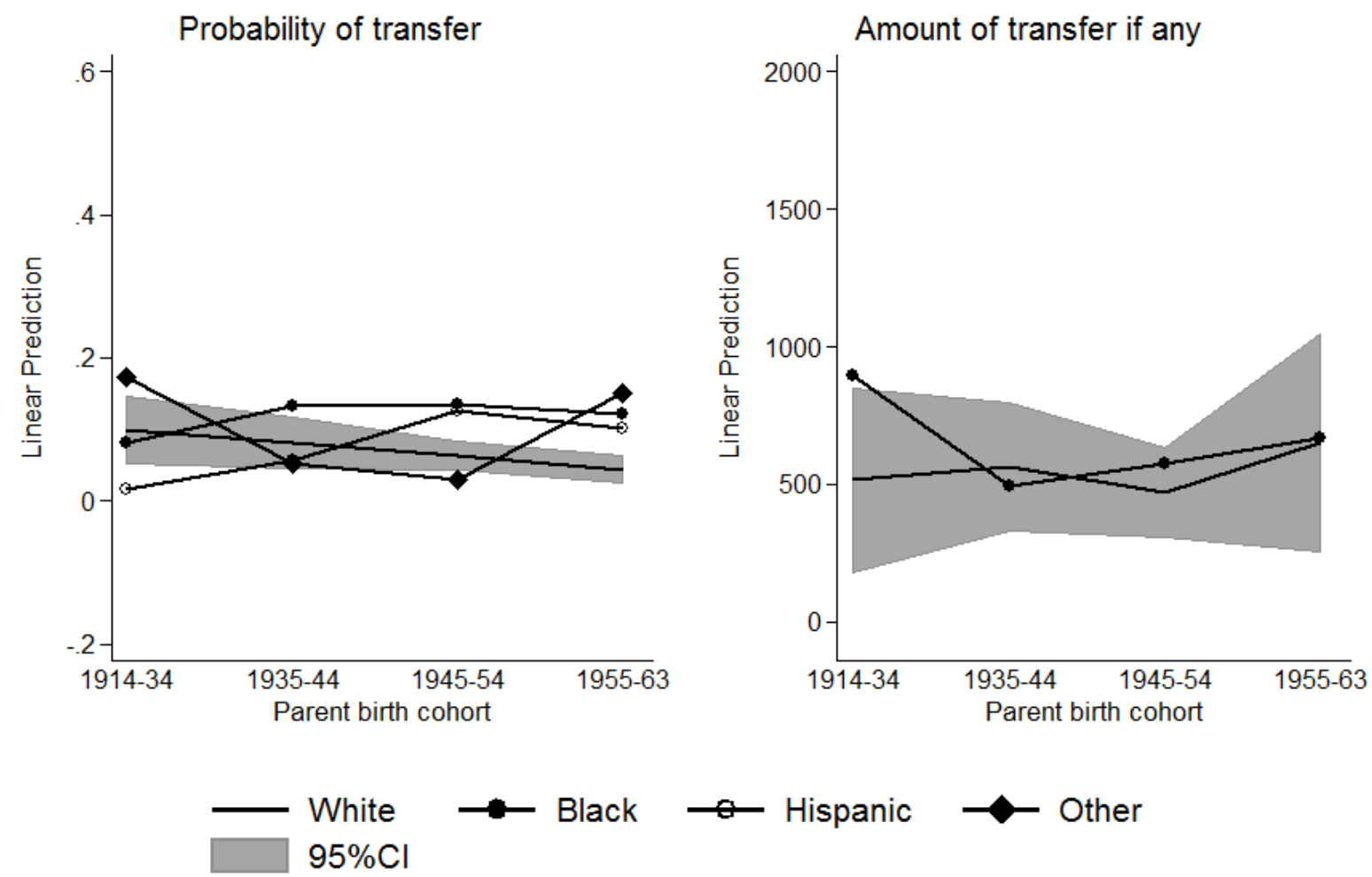

Note: Full regression results are available in Appendix Table A1, Models 4 (probability) and 8 (amount). Models of amounts exclude Hispanic and Other race respondents. 
Appendix Table A1. Regression Models with Birth Cohort by Race Interactions Used to Plot Figures 1-4

\begin{tabular}{|c|c|c|c|c|c|c|c|c|}
\hline \multirow[b]{4}{*}{ Variables } & \multicolumn{4}{|c|}{ Probability } & \multicolumn{4}{|c|}{ Amount, if any } \\
\hline & \multicolumn{2}{|c|}{ Parent gives } & \multicolumn{2}{|c|}{ Parent receives } & \multicolumn{2}{|c|}{ Parent gives } & \multicolumn{2}{|c|}{ Parent receives } \\
\hline & Time & Money & Time & Money & Time & Money & Time & Money \\
\hline & (1) & (2) & (3) & (4) & (5) & (6) & (7) & (8) \\
\hline \multicolumn{9}{|l|}{ Parent is } \\
\hline Female & 0.00949 & $-0.0393 *$ & $0.144^{* *}$ & $0.0688 * *$ & 82.10 & -343.7 & 14.96 & 128.1 \\
\hline Born 1914-34 & ref & ref & ref & ref & ref & ref & ref & ref \\
\hline Born 1935-44 & 0.0464 & -0.0488 & $-0.138 * *$ & -0.0258 & 161.7 & 1,304 & $-325.6 * *$ & -47.16 \\
\hline Born 1945-54 & $0.148 * *$ & -0.0448 & $-0.140 * *$ & -0.0395 & -36.81 & -53.86 & $-368.5^{* *}$ & -106.4 \\
\hline Born 1955-63 & $0.212 * *$ & -0.0662 & -0.0513 & $-0.0602 *$ & -94.50 & -115.5 & $-362.3^{* *}$ & -92.76 \\
\hline Black & $-0.0605^{*}$ & $-0.145^{* *}$ & -0.0918 & -0.0226 & -108.6 & $-3,174^{*}$ & -156.9 & -35.43 \\
\hline Hispanic & $-0.105^{* *}$ & $-0.192+$ & -0.182 & $-0.0952 * *$ & & & & \\
\hline Other race & $-0.105+$ & $-0.352 * *$ & 0.277 & 0.107 & & & & \\
\hline \multicolumn{9}{|l|}{ Child is } \\
\hline Age $36-50$ & $-0.0742 * *$ & $-0.0772 * *$ & 0.0146 & 0.00858 & -48.80 & 163.0 & 58.57 & 33.32 \\
\hline Age 51+ & $-0.156^{* *}$ & $-0.0746 *$ & -0.0180 & -0.0264 & -262.1 & 2,796 & 180.4 & -294.4 \\
\hline Female & $0.0630 * *$ & 0.00427 & $-4.45 e-05$ & $0.0139+$ & 43.77 & -358.7 & $125.5^{* *}$ & -20.19 \\
\hline \multicolumn{9}{|l|}{ Parent has } \\
\hline 2 children & $-0.0948 * *$ & $-0.0686 *$ & $-0.0889 * *$ & -0.0258 & -157.3 & -897.7 & -130.9 & -77.14 \\
\hline 3 children & $-0.141^{* *}$ & $-0.160 * *$ & $-0.109 * *$ & -0.0285 & $-171.5+$ & $-1,630+$ & $-208.0 *$ & -69.44 \\
\hline 4+ children & $-0.210 * *$ & $-0.259 * *$ & $-0.153^{* *}$ & $-0.0704 * *$ & -75.46 & $-2,204 *$ & -120.6 & 150.7 \\
\hline \multicolumn{9}{|l|}{ Wealth difference } \\
\hline Decile of wealth difference & $0.00713^{* *}$ & $0.0251 * *$ & -0.00257 & 0.00156 & -12.27 & $310.7 * *$ & -8.349 & -13.86 \\
\hline Miles apart $\times 100$ & $-0.0103 * *$ & $0.00428 *$ & $-0.0102 * *$ & 0.00192 & -6.774 & $-91.54+$ & -3.598 & 8.316 \\
\hline Same HH & $0.0427 *$ & $0.115^{* *}$ & $0.0549 * *$ & -0.00882 & $141.5 *$ & $1,491 * *$ & 112.7 & 138.1 \\
\hline \multicolumn{9}{|l|}{ Parent cohort by race interactions } \\
\hline Born 1935-44 × Black & 0.0719 & 0.0507 & 0.0796 & 0.0861 & 299.4 & $-1,211$ & $546.9+$ & 30.93 \\
\hline Born 1935-44 × Hispanic & 0.127 & -0.0128 & 0.145 & $0.0925+$ & & & & \\
\hline Born 1935-44 × Other race & -0.0931 & 0.148 & -0.305 & -0.129 & & & & \\
\hline Born 1945-54 × Black & 0.000260 & $0.121^{*}$ & 0.0862 & $0.0964 *$ & $297.9 * *$ & 1,394 & 352.7 & 133.7 \\
\hline
\end{tabular}

-continued- 
Appendix Table A1. Regression Models with Birth Cohort by Race Interactions Used to Plot Figures 1-4 (cont'd)

\begin{tabular}{|c|c|c|c|c|c|c|c|c|}
\hline \multirow[b]{4}{*}{ Variables } & \multicolumn{4}{|c|}{ Probability } & \multicolumn{4}{|c|}{ Amount, if any } \\
\hline & \multicolumn{2}{|c|}{ Parent gives } & \multicolumn{2}{|c|}{ Parent receives } & \multicolumn{2}{|c|}{ Parent gives } & \multicolumn{2}{|c|}{ Parent receives } \\
\hline & Time & Money & Time & Money & Time & Money & Time & Money \\
\hline & $(1)$ & $(2)$ & (3) & (4) & (5) & (6) & (7) & (8) \\
\hline Born 1945-54 × Hispanic & -0.0171 & 0.123 & 0.196 & $0.160 * *$ & & & & \\
\hline Born 1945-54 × Other race & 0.0455 & $0.360 * *$ & -0.210 & -0.141 & & & & \\
\hline Born 1955-63 × Black & $-0.0838 *$ & $0.112^{*}$ & -0.00368 & $0.104^{*}$ & $359.8 * *$ & 1,666 & 442.9+ & 200.8 \\
\hline Born 1955-63 × Hispanic & $-0.167 * *$ & 0.0858 & 0.0312 & $0.159 * *$ & & & & \\
\hline Born 1955-63 × Other race & -0.119 & $0.393 * *$ & -0.340 & 0.00345 & & & & \\
\hline Constant & $0.344 * *$ & $0.429 * *$ & $0.437 * *$ & $0.108 * *$ & $451.5^{*}$ & 2,685 & $558.1 * *$ & $564.6^{*}$ \\
\hline Observations & 5,204 & 5,204 & 5,204 & 5,204 & 1,572 & 1,529 & 1,209 & 422 \\
\hline R-squared & 0.123 & 0.114 & 0.063 & 0.041 & 0.043 & 0.057 & 0.078 & 0.046 \\
\hline
\end{tabular}

Notes: Robust standard errors not shown; ${ }^{* *} \mathrm{p}<0.01,{ }^{*} \mathrm{p}<0.05,+\mathrm{p}<0.1$; reference categories not indicated to save space; wealth differences computed as the decile of parent wealth minus child wealth; Models 5 through 8 exclude Hispanic and Other race respondents. 


\section{RECENT WORKING PAPERS FROM THE CENTER FOR RETIREMENT RESEARCH AT BOSTON COLLEGE}

Guardianship and the Representative Payee Program

Anek Belbase and Geoffrey T. Sanzenbacher, August 2017

The Relative Effects of Economic and Non-Economic Factors on Taxpayers' Preferences Between Front-Loaded and Back-Loaded Retirement Savings Plans

Andrew D. Cuccia, Marcus M. Doxey, and Shane R. Stinson, July 2017

Social Security and Total Replacement Rates in Disability and Retirement

Mashfiqur R. Khan, Matthew S. Rutledge, and Geoffrey T. Sanzenbacher, May 2017

An Experimental Analysis of Modifications to the Survivor Benefit Information within the Social Security Statement

Jeffrey Diebold and Susan Camilleri, May 2017

Actuarial Inputs and the Valuation of Public Pension Liabilities and Contribution Requirements: A Simulation Approach

Gang Chen and David S. T. Matkin, May 2017

Why Are U.S. Households Claiming Social Security Later?

Wenliang Hou, Alicia H. Munnell, Geoffrey T. Sanzenbacher, and Yinji Li, April 2017

Rising Inequality in Life Expectancy by Socioeconomic Status

Geoffrey T. Sanzenbacher, Anthony Webb, Candace M. Cosgrove, and Natalia S. Orlova, April 2017

The Effect of Job Mobility on Retirement Timing by Education

Geoffrey T. Sanzenbacher, Steven A. Sass, and Christopher M. Gillis, February 2017

Would Reducing the Price of Employing an Older Worker Improve Labor Market Outcomes by Socioeconomic Status? Evidence from Health Insurance Premium Restrictions

Matthew S. Rutledge and Caroline V. Crawford, December 2016

The Impact of Massachusetts Health Insurance Reform on Labor Mobility

Norma B. Coe, Wenliang Hou, Alicia H. Munnell, Patrick J. Purcell, and Matthew S. Rutledge, December 2016

Work, Retirement, and Social Networks at Older Ages

Eleonora Patacchini and Gary V. Engelhardt, November 2016

All working papers are available on the Center for Retirement Research website (http://crr.bc.edu) and can be requested by e-mail (crr@bc.edu) or phone (617-552-1762). 